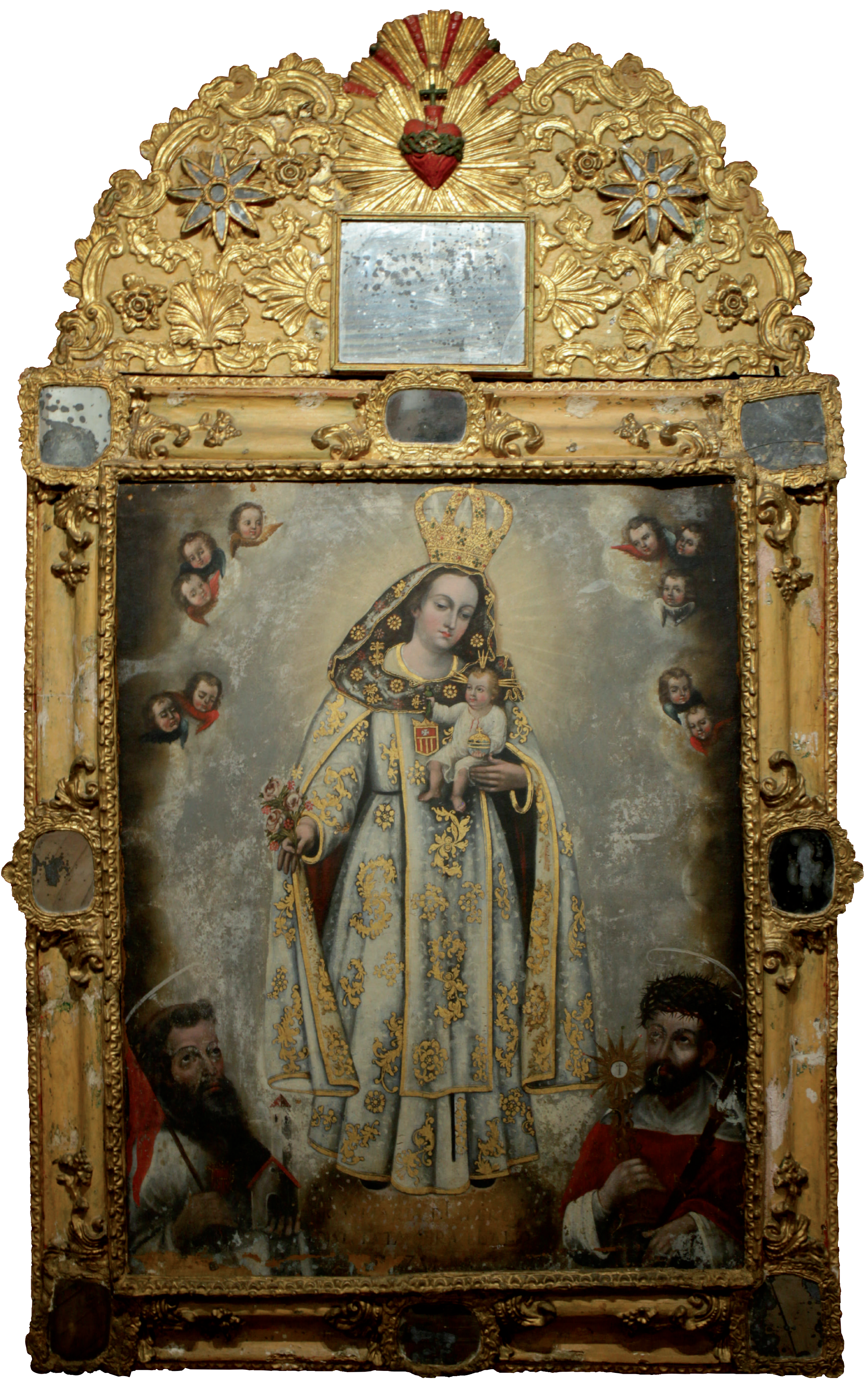




\title{
Mujer y arte en la Real Audiencia de Quito. Una pintura de la Virgen de la Merced en el monasterio de Las Conceptas de Cuenca (Ecuador)
}

\author{
Women and Art at the Real Audiencia of Quito: A painting of the Virgin of Mercy \\ in the Monastery of Las Conceptas in Cuenca (Ecuador)
}

\author{
Macarena Montes Sánchez \\ Universidad de Cuenca, Ecuador \\ macarena.montes@ucuenca.edu.ec \\ https://orcid.org/0000-0001-7026-689X
}

Sergio Ramírez González

Universidad de Málaga, España

srg@uma.es

https://orcid.org/0000-0003-3365-1435

Recepción: 02/07/2020 | Aceptación: 10/09/2020

\section{Resumen}

El papel desempeñado por las artistas en la América colonial del siglo XVIII continúa siendo un tema de candente debate y del que falta todavía mucho por investigar. La escasez de oportunidades y los obstáculos encontrados no excluye el camino de algunas de ellas hacia el aprendizaje y posterior desarrollo de la pintura, de modo que, desde su estado laico o religioso, pudieron llegar a alcanzar cierta nombradía. El presente trabajo analiza justamente el panorama suscitado al respecto en la Real Audiencia de Quito a través de una serie de ejemplos, que derivarán en el caso concreto del lienzo de la Virgen de la Merced del Museo de Las Conceptas en Cuenca. Alrededor de la autora, las circunstancias históricas de la obra y sus características estéticas e iconográfícas girará este estudio, con visos de intentar desentrañar diferentes incógnitas.

\section{Abstract}

The role played by female artists in $18^{\text {th }}$ century colonial America continues to be a subject of heated debate and one in which further research is needed. The lack of opportunities and the obstacles encountered did not prevent some female artists, whether religious or not, from learning and developing their skills, and attaining a certain degree of acclaim. The present work analyses a series of examples related to the Real Audiencia of Quito, in particular the case of the painting known as the Virgen de la Merced (Virgin of Mercy) in the Museum of Las Conceptas in Cuenca. This investigation will focus on its author, history, and aesthetic and iconographic characteristics, in an attempt to unravel varying mysteries related to the artwork.
Palabras clave

Virgen de la Merced

Sor María de la Merced

Concepcionistas

Iconografía mercedaria

Cuenca

Siglo XVIII

Keywords

Virgin of Mercy

Sister Maria of Mercy

Conceptionists

Mercedarian Iconography

Cuenca

$18^{\text {th }}$ Century

Cómo citar este trabajo / How to cite this paper:

Montes Sánchez, Macarena, y Sergio Ramírez González. "Mujer y arte en la Real Audiencia de Quito. Una pintura de la Virgen de la Merced en el monasterio de Las Conceptas de Cuenca (Ecuador)." Atrio. Revista de Historia del Arte, no. 26 (2020): 88 - 118. https://doi.org/10.46661/atrio.5096

(C) 2020 Macarena Montes Sánchez y Sergio Ramírez González. Este es un artículo de acceso abierto distribuido bajo los términos de la licencia Creative Commons Attribution-NonCommercial-ShareAlike 4.0. International License (CC BY-NC-SA 4.0). 


\section{Introducción}

Refería el filósofo escocés David Hume que "la belleza de las cosas existe en el espíritu del que las contempla". Eso mismo podría aplicarse a las numerosas obras de arte que, en sus distintas modalidades, tenían cabida durante la Edad Moderna en las clausuras de los conventos femeninos. Eran las religiosas, justo es decir, quienes vivían recluidas entre sus muros y cuyo principal cometido y misión pasaba por perfeccionar sus virtudes espirituales. Los testimonios de artes plásticas que aderezaron no solo los templos del complejo, sino también otras estancias como los coros, refectorios, salas De profundis, salas capitulares o celdas, entre otras, poseían una triple funcionalidad, más allá de la ornamental, que las hacía imprescindibles en el discurrir cotidiano de la comunidad. Por un lado, reforzaban los canales pedagógicos a la hora, más que de entender -pues se presuponía una cierta cultura en la mayoría de las monjas-, de profundizar en los contenidos de las Sagradas Escrituras y los textos místicos y hagiográficos propios de la orden o de extensión generalizada.

En segundo lugar, la mayoría de estas obras servían a dichas féminas de aparato inspirador a la hora de incentivar devociones particulares y aumentar en todo lo posible la espiritualidad personal. De modo que tales representaciones, sus personajes e historias, iban a ser también el espejo donde mirarse ante la falta de oportunidades sociales y religiosas fuera del inmueble. Es decir, que se convirtió en el modelo perfecto de cara a experimentar en sus propias carnes, repetido en las formas y actitudes, todo el repertorio de sucesos maravillosos acaecidos a los grandes exponentes de la tradición cristiana, convirtiendo de paso al convento en un verdadero espacio del milagro. Tales utilidades, bien conocidas, iban a completarse con una tercera de más puntual consideración, aunque no por ello menos sustancial. Nos referimos a la contemplación e interacción con el testimonio artístico por mera recreación particular, entendida como vínculo que permitía a las religiosas alcanzar la captación y disfrute de la belleza en toda su esencia. Algo que, en principio, no les estaba reservado a su estado, pero que formó parte asimismo de su vida en calidad de aproximación al exterior y vía de escape a los continuos rigores.

Todo esto fue consustancial a los conventos femeninos de la Real Audiencia de Quito y, por supuesto, a la casa de las religiosas concepcionistas de Cuenca. Sus componentes actuaron ante las obras artísticas no solo como espectadoras, sino también como principales promotoras auspiciando el encargo y/o compra con una férrea adaptación a los temas y a la estética imperante del momento, sin obviar su papel ante una 
donación particular de familiares o personas conocidas. En otras ocasiones, y esta es la posibilidad que más nos interesa, las monjas desempeñaron el papel de autora y artista, tal como se demuestra en la pintura de la Virgen de la Merced objeto de estudio. De esta manera, y así fue común en los numerosos casos experimentados tanto en Hispanoamérica como en Europa, se cerraba un círculo donde se apostó por la economía de medios, la mejor comprensión y adaptación a los temas y, por qué no decirlo, propiciando el alejamiento de todo contacto con artistas laicos.

\section{Artistas en la Real Audiencia de Quito}

Aunque las historias de mujeres dentro de la historia del arte ecuatoriano ya dejaran de ser una novedad, es una realidad que aún queda mucho por descubrir e interpretar. Mantener el avance en el conocimiento en esta rama de estudio es una necesidad, pues falta incorporar la perspectiva de género, de forma transversal, a las investigaciones, los manuales y la docencia en la historia del arte ecuatoriano.

La escasez de fuentes documentales para definir la autoría de algunas obras de mujeres artistas en la Audiencia de Quito, muchas de ellas en el anonimato o muy dispersas, no ha permitido la elaboración de biografías rigurosas ${ }^{1}$, cuando además, las obras de estas artífices son normalmente menos numerosas. Tales circunstancias inciden en la exclusión o la falta de definición y presencia de las artistas de los inventarios o catálogos sobre el arte colonial quiteño.

Las distintas realidades sociales y culturales de las mujeres, nos permiten también entender la complejidad de los entornos, jerarquías y relaciones sociales. En la sociedad virreinal, dos eran las salidas para la mujer al llegar a la edad adulta: la vida en familia o la vida monacal. La soltería como estado civil, no era muy bien vista dentro de la estructura social patriarcal, por lo que algunas instituciones religiosas optaron por recogerlas como seglares. Estas damas laicas, declarándose en estado de celibato y en libre uso de sus bienes, podían destinar su capital y recursos para impulsar obras pías.

1. Importantes aportes sobre mujeres artistas quiteñas del siglo XVIII presentan los estudios realizados por Carmen Fernández-Salvador, Alexandra Kennedy Troya, Adriana Pacheco Bustillos, Ángel Justo Estebaranz o el artículo de Inmaculada Martín Martín, "Isabel de Santiago: una pintora quiteña del siglo XVII," De Arte. Revista de Historia del Arte, no. 7 (2008): 129-152. 
Las mujeres casadas, unidas por matrimonio con alguien de su misma condición social, estaban sujetas a la dote que administraba el marido. En algunos testamentos se puede apreciar la diferenciación entre bienes pertenecientes al marido, conyugales o bienes adquiridos. La inversión de sus recursos "en una sociedad que recluye a las mujeres en el ámbito de lo privado, solo podía aceptar este tipo de actividad cuando el fin lo justificase, es decir, cuando la obra de arte se convierte en un instrumento de prestigio o de salvación"2; por lo tanto, se justifican siempre y cuando lograsen las gracias espirituales. Si la mujer quedaba en estado de viudez, debía transar su situación económica y social, pudiendo incorporarse a una actividad mercantil o gremial, lo que nos lleva a pensar en la necesidad de profundizar en el desarrollo del proceso productivo en los talleres artesanales. También, las viudas podían volver a optar por un nuevo matrimonio; al morir el esposo tenían libre cauce para administrar su patrimonio, lo que facilita a los investigadores el estudio de las fuentes documentales. De modo contrario, al estar casadas los documentos o contratos eran firmados por el marido a pesar de que la autoría de la obra o la promoción artística fuera iniciativa de la mujer. La institución del matrimonio y la dote era casi inexistente entre mestizos o indígenas.

Resguardadas económicamente por sus actividades financieras, las monjas lograron defender y mantener su autonomía de un mundo que les exigía sumisión y recato ${ }^{3}$. La estructura de la sociedad colonial tardía se reprodujo en los muros del monasterio. Las jerarquías familiares son construcciones humanas y, por lo tanto, susceptibles de ser decodificadas a partir de los discursos y la lectura de experiencias. Existía una clara escala social dentro de los muros protagonizadas por las monjas de velo negro, vicarias y discretas, en el escalafón superior, y las esclavas mulatas o negras en el inferior. Las expresiones artísticas, fundamentalmente de tipo religioso, son el reflejo de todos estos roles y relaciones en la sociedad colonial.

Desde el punto de vista de la mujer como creadora de la obra artística, la historiografía tradicional del arte ecuatoriano nos revela algunos datos tratados siempre dentro del discurso de la excepción o la excelencia. Debido a que el sistema le mantenía fuera de toda estructura paragremial, dos fueron los ámbitos en los que la mujer pudo ejercer la

2. Ana Aranda Bernal, "La participación de las mujeres en la promoción artística durante la Edad Moderna," Goya, Revista de Arte, no. 301$302(2004): 234$.

3. Véase de Christiana Renate Borchart de Moreno, La Audiencia de Quito: aspectos económicos y sociales(siglos XVI-XVIII)(Quito: Ediciones del Banco Central y Ediciones Abya-Yala, 1998) o "La imbecilidad y el coraje, la participación femenina en la economía colonial 17801830," Revista Complutense de Historia de América, no. 17 (1991): 167-182. 
Fig. 1. Retrato fotográfico de monjas pintoras de Cuenca, c. 1910. (Fondo fotográfico del Museo Pumapungo, Cuenca).

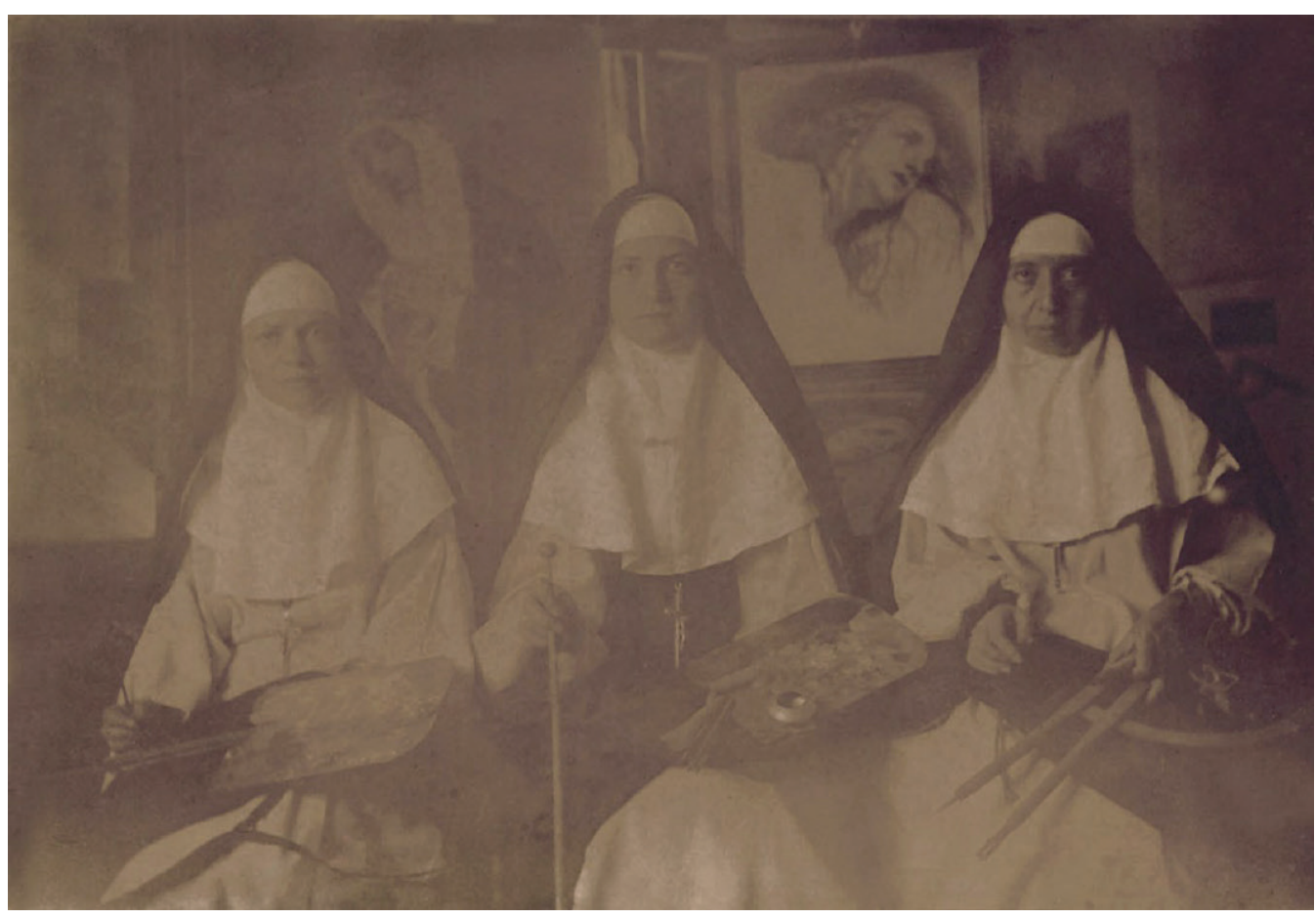

profesión artística: la formación podía darse en el ámbito privado, en el taller familiar, como es el caso de Isabel de Santiago, o dentro de la clausura (Fig. 1).

La biografía de Isabel de Santiago (1660-1714), una de las pocas mujeres en obtener reconocimiento dentro del arte colonial quiteño, revela las dificultades que experimentó para agremiarse. Por ser hija del famoso pintor Miguel de Santiago heredó el taller paterno y obtuvo un estatus profesional, pero no pudo optar al examen que le permitía recibir un grado, quedando fuera de todo trato igualitario en la organización gremial. El arzobispo Federico González Suárez la distingue por ser una artista que "sobresalía en la pintura y manejaba el pincel con admirable delicadeza" ${ }^{\prime}$, aludiendo a esa supuesta sensibilidad en la que debe enmarcarse la temática de las artistas.

Repartidos a lo largo del territorio de la Audiencia de Quito, cuatro son las órdenes que establecieron monasterios o conventos femeninos en la sociedad virreinal: concepcionistas (Quito, Loja, Pasto, Cuenca, Riobamba e Ibarra), la orden de Santa Catalina de Siena (Quito), clarisas (Quito) y las carmelitas descalzas (Quito, Latacunga y Cuenca), a más del beaterio quiteño bajo la tutela de los mercedarios ${ }^{5}$. Dentro de estos claustros, son dos las mujeres más reconocidas por la historiografía realizando esta labor

4. Federico González Suárez, Historia General de la República del Ecuador (Quito: Imprenta del Clero, 1903), 7: 139.

5. María Isabel Viforcos Marinas, "El beaterio quiteño de Nuestra Señora de La Merced y sus fallidos intentos de transformación del convento (1730-1758), "en I Congreso Internacional del monacato femenino en España, Portugal y América: 1492-1992 (León: Universidad de León, 1993), 357-366. 
artística; nos referimos a María Estefanía de San José y a Ángela de la Madre de Dios Manosalvas. Su estado como religiosas les permitía ejercer esta actividad con un mayor grado de libertad; de hecho, todos estos monasterios se convirtieron en centros de producción y las religiosas en generadoras de obras, mayormente anónimas.

Nacida en la villa de Riobamba, la religiosa carmelita María Estefanía Dávalos y Maldonado o sor María Estefanía de San José(1720-1801) profesó en el monasterio del Carmen Moderno en Quito. Sobrina del científico Pedro Vicente Maldonado, colaborador de la Misión Geodésica Francesa a su paso por la Audiencia de Quito, fue visitada junto a su familia por Charles María de La Condamine, quien registró en su diario de viajes que:

Don Antonio tenía tres hermanas; la segunda de ellas, de 16 años, traducía a primera vista a Moreri. Veíase en la casa de hacienda un torreón, adornado con muchas obras delicadas, muy bien ejecutadas por las manos de estas tres jóvenes. La mayor estaba dotada de un talento universal: tocaba el arpa, el clavicordio, la guitarra, el violín y la flauta; mejor dicho, todos los instrumentos que llegaban a sus manos. Sin maestro alguno pintaba en miniatura y al óleo. Yo mismo ví en su caballete un cuadro que representaba la Conversión de San Pablo, con treinta figuras correctamente dibujadas, para el cual había echado mano de los malos colores que habían en el país. Con tantas prendas para agradar en el mundo, esta joven no deseaba más que hacerse carmelita y retardaba el cumplimiento de sus deseos; tan sólo el amor tierno que profesaba a su padre, el cual, después de haber resistido largo tiempo, le dio al fin su consentimiento y así profesó en Quito el año de $1742^{6}$.

Dedicada a la escultura, entre sus obras dentro del monasterio destaca la Virgen del Carmen, venerada en el altar mayor de la iglesia, la Virgen del Tránsito y un Corazón de María. El historiador del arte José Gabriel Navarro señala que la hermana menor de sor María de San José, Magdalena, se distinguió también en la pintura y escultura, siendo de su autoría el Señor de la Resurrección y Santa Teresa en el mismo claustro.

Otra religiosa carmelita es la madre Ángela de la Madre de Dios Manosalvas, tía del famoso pintor quiteño Juan Manosalvas y al que se dice dictó sus primeras clases de dibujo. De ella se indica que "en el mismo monasterio se distinguió también como pintora la Madre Ángela de la Madre de Dios Manosalvas, que había sido discípula de Nicolás Cabrera e inició en el arte a su sobrino el pintor Juan Manosalvas. La madre Manosalvas doró los ángeles tallados por la Madre María de San José Dávalos"8.

6. Charles Maria de La Condamine, Journal de voyage fait par ordre du Roi, a L'Equateur, servant d'introduction historique a la mesure des trois premiers degrés du méridien (París: Imprimerie Royale, 1751), 66-67; José María Vargas, El arte ecuatoriano (Puebla: Editorial J. M. Cajica, 1959), 231.

7. José Gabriel Navarro, La escultura en el Ecuador durante los siglos XVI, XVII y XVIII (Quito: Ed. Fundación José Gabriel Navarro y TRAMA, 2006), 210.

8. Vargas, El arte ecuatoriano, 231. 
Aunque es importante que esta parte del estudio se dedique al papel de la mujer como artista, no podemos olvidar un campo, hasta hace poco olvidado, como es el de la mujer en calidad de promotora artística, es decir, ejerciendo un papel protagónico en la financiación y la elección de temas o artistas. Aunque es difícil entender las circunstancias que muchas veces les llevó a impulsar una obra o el motivo para su adquisición, esta labor de mecenazgo contribuyó a la creación de gran parte del patrimonio artístico del periodo colonial, del que podemos disfrutar a día de hoy.

Tales mujeres, mayoritariamente pertenecientes a clases privilegiadas, pudieron también ejercer la promoción desde espacios que le facilitasen un manejo económico en cargos de poder, como los conventos femeninos de clausura y, donde además, el fin religioso pudiera justificar los medios. Aún reconociendo el voto de pobreza, las abadesas o prioras, que pertenecen en su mayoría a la clase dominante, ejercen decisiones relacionadas con la producción de bienes culturales. Esta solvencia económica permite realizar contratos con maestros o artesanos, locales o de otras ciudades, o bien realizar adecuaciones y ampliaciones de sus propios espacios.

En el caso de las concepcionistas de Quito, en las Relaciones del Obispado de Quito, Rodriguez Docampo señala cuando describe al convento de monjas de la Concepción de Nuestra Señora la Real a la abadesa Mariana de Santo Domingo "de gran gobierno, virtud, y vida ejemplar"9. Elegida por tres períodos, en la primera mitad del siglo XVII, durante su gobierno impulsó las obras para culminar la fábrica del templo.

A nivel local, es interesante el caso de la priora Rosalía de San Luis Gonzaga. Dentro del monasterio del Carmen de la Asunción de la ciudad de Cuenca, se encuentra, sin lugar a dudas, uno de los ciclos de pinturas murales más importantes del arte colonial quiteño. Esta obra situada en el refectorio y el anterrefectorio del monasterio, refleja, con una temática única, la vida cotidiana de la sociedad colonial. En el cielo raso del refectorio, en un programa iconográfico lleno de motivos y detalles decorativos y simbólicos, se disponen tres leyendas, a manera de vítores, a partir del paño de gala y el reflejo del sonido de la trompeta del ángel(Fig. 2): "VIVA VIVA LA MADRE ROSALIA DE SAN LUIS GONSAGA/ PRELADA DE ESTE SANTO MONASTERIO POR LOS AÑOS DE 1807/ EN LAS [ sic] QUE MANDO CONSTRUIR ESTA PIESA VIVA". Aparte de indicarnos la fecha en la que se

9. Diego Rodríguez Docampo, "Descripción y relación del Estado eclesiástico del Obispado de San Francisco de Quito, que se ha hecho por mandado del Rey Nuestro Señor en virtud de su Real Cédula dirigida al IIImo. Sr. D. Agustín de Ugarte Saravia, Obispo de Quito, del Consejo de S. M. Por cuya orden la hizo Diego Rodríguez Docampo Clérigo, Presbítero Secretario del Venerable Deán y Cabildo de aquella Catedral. Año de 1650," en Relaciones geográficas de Indias (Madrid: Ed. Atlas, 1965), 207-322. 


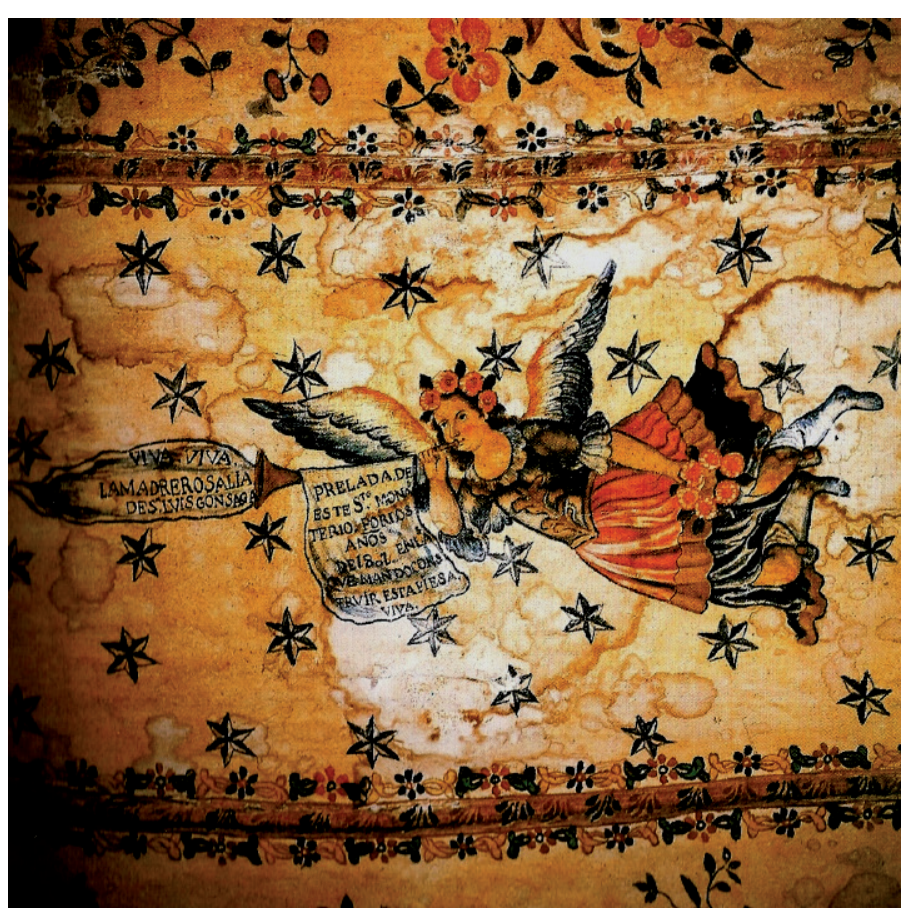

Fig. 2. Anónimo, detalle de pintura mural del refectorio del monasterio del Carmen de la Asunción en Cuenca, con la leyenda referente a la priora Rosalía de san Luis Gonzaga. (Cortesía de la Biblioteca Víctor Manuel Albornoz, Museo Pumapungo, Ministerio de Cultura, Cuenca). concluye la obra ${ }^{10}$, refiere también el papel de promotora e impulsora de esta religiosa. Las otras dos inscripciones son dirigidas a las monjas y al capellán del monasterio, por haber comandado las reformas.

Pero la labor de esta religiosa no acaba aquí; conocido es por todos que dentro de los muros de los monasterios se han producido repintes, retoques y labores de restauración y conservación de las obras que allí permanecen, a veces de forma artesanal, o bien realizando contratos a personas externas. Una de las inscripciones más llamativas que se han encontrado en los lienzos de este monasterio es la perteneciente a la Coronación de la Virgen o Lucero de la Grada, tal y como lo conocen las monjas debido a su ubicación dentro del claustro. De 340 centímetros de alto por 220 de ancho, esta gran obra revela un interesante programa iconográfico. En la parte inferior del cuadro se congregan los apóstoles que imploran alabanzas que surgen de la boca, inscritas en el conjunto a modo de salves. Ocupando la parte central del lienzo, la Virgen asciende al cielo en una nube de querubines y ángeles; en la parte superior, el Espíritu Santo en forma de paloma irradia luz, en tanto a Ios lados Cristo y el Padre Eterno coronan a la Virgen. En el espacio inferior del lienzo se encuentra la leyenda: "El año 1813 se retocó este lienzo a petición de la Rev. Madre Rosalía de San Luis Gonzaga, nuestra actual Prelada, y en concurso de sus venerables súbditas quienes devotamente concurrieron con sus limosnas y otras doncellas particulares que viven en este santo Monasterio llevadas de la devoción, a quienes les pague Dios y su Santísima Madre". Además de la labor de conservación, se puede apreciar por esta inscripción la relación de solidaridad entre monjas y seglares o particulares que habitaban el monasterio y que contribuyen con sus obras ${ }^{11}$.

10. Tradicionalmente ha sido transcrita y considerada por otros autores como 1801.

11. Macarena Montes Sánchez, "La participación de la mujer en el patrimonio artístico de Cuenca a fines de la Colonia," Boletín de la Academia Nacional de Historia, XCl, no. 188 (2013): 41-86. 
Dentro de este contexto de fomento a la producción artística, las religiosas constituyen para los artistas una importante clientela. Por ejemplo, si una orden religiosa femenina decidía construir un nuevo retablo, debía comunicarlo al vicario general de monjas y después de su aprobación, proceder con el encargo. La priora convocaba a concurso o Io adjudicaba directamente. Como en el caso de las pinturas murales del monasterio del Carmen, normalmente se contaba con el capellán al que se le nombraba como "diputado" y un administrador para coordinar todo el proceso. La prelada anotaba en el libro de cuentas las construcciones y reparaciones menores. Este es el caso de la abadesa María del Sacramento (1677-1686) que participó en los inicios de la construcción de la iglesia de Las Conceptas en Cuenca, describiendo que en los primeros cuatro años el monasterio:

\footnotetext{
todos los días dando de comer a indios, peones, albañiles, carpinteros, canteros y dichos sus oficiales y a los mayordomos españoles que asistían y que han habido ocasiones que dábamos de comer a doscientas personas, pero las que cotidianamente asistían cincuenta o sesenta, y también los regalos que les dábamos a los que entraban con piedras para obligarlos y tenerlos gratos, y también hemos gastado cuatro ventanas que hemos mandado hacer de madera para coro y puertas y la escalera del que hemos pagado así la madera como los oficiales y también los ladrillos y tejas de dichas escaleras y adobes ${ }^{12}$.
}

Se llegaría a gastar ese año en la fábrica 31.145,60 pesos. Posteriormente, se anotarán también los gastos de los pagos a los maestros escultores y doradores por la hechura del tabernáculo y el sagrario.

\section{El monacato femenino en Cuenca: las concepcionistas}

Antes de abordar de lleno el estudio de la pintura de referencia resulta necesario ofrecer unas leves pinceladas acerca de la historia de la institución a la que pertenece, con vistas a entender mucho mejor el contexto en el que se creó, o al que llegó en un momento dado, como base fundamental de su sentido y propia existencia. El monasterio de la Pura y Limpia Concepción de Cuenca ha jugado un papel fundamental y activo en el plano económico, social y cultural en la configuración del Corregimiento y Gobernación de Cuenca.

Al ser el primer monasterio femenino de la ciudad y el tercero de esta orden en territorio ecuatoriano ${ }^{13}$, en el momento de su fundación, un 3 de junio de 1599, surge con la

12. 1682-1711, 2-5, Archivo Nacional de Historia (ANH/C), Cuenca.

13. El primer monasterio de esta orden en fundarse fue en Quito en 1577, y el segundo en Loja en 1597. 
intención de ofrecer una salida a "muchas doncellas pobres, hijas y nietas de conquistadores, que deseaban tomar estado de religiosas"14. Para su puesta en marcha viajan tres monjas profesas desde la ciudad de Quito; una de ellas, Magdalena de San Juan, se convertirá en la primera abadesa del monasterio de Cuenca, acompañada por Leonor de la Trinidad como vicaria. Las casas para albergar a esta congregación, a tres cuadras de la plaza central, fueron donadas por Leonor Ordóñez, quien estuviera casada con Benito de Amendaña (tesorero del cabildo), para que sus tres hijas -Leonor, Gerónima y Ángela- pudieran vestir el hábito de religiosas. El obispo Luis López de Solís la describe como "la mejor casa de toda la ciudad, y más cómoda para el dicho efecto por estar como está, toda alrededor muy bien cercada y con edificios bastantes para su habitación y con iglesia, coro alto, bajo y una fuente de agua adentro"15.

Al cumplirse diez años de su fundación eran cuarenta las mujeres que habían ingresado a la vida monástica. Para 1722, el número ascendió a setenta y dos ${ }^{16}$; dicho crecimiento demográfico es debido a que la orden no establecía un número fijo de religiosas ${ }^{17}$, solo presente cuando peligraba la segura sustentación de las moradoras a través de las rentas y limosnas.

Pero no solo de monjas estaba habitado el monasterio; la historiadora del arte Alexandra Kennedy, tras realizar la catalogación del archivo de esta orden, definió al monasterio como "una ciudad dentro de otra" por el número de habitantes que llegaron a integrar la vida en clausura y por la estructura social de la misma. El dato más revelador, aparte de los informes emanados por las visitas del obispo o su delegado, procede del censo realizado en Cuenca en el año de $1778^{18}$. Este documento indica que existían un total de 189 mujeres en recogimiento, entre ellas: religiosas de coro y velo negro (27), de velo blanco (1), novicia (1), criadas de la comunidad, indias (27), adultas en recogimiento (16), mestizas criadas (33), mulatas libres (9) e indias, algunas criadas de las particulares y otras que viven en recogimiento (75). Sorprende el número elevado de esclavas y sirvientas, pues las disposiciones prohibían más de una criada por cada diez monjas. También el texto hace alusión a la presencia de cinco párvulas españolas, a pesar de que la entrada

14. Alexandra Kennedy Troya y Marcia Sigüenza Crespo, Monasterio de las Conceptas. Catálogo del Archivo Histórico (Cuenca: Fundación Paul Rivet, 1990), 15. En: 1599, 1-4, fol.10, Archivo Histórico Monasterio de Las Conceptas (AHMC/C), Cuenca.

15. Fray Luis [López de Solís], Obispo de San Francisco de Quito, Carta, 3 de junio de 1599, 1-4. fol. 3, AHNC/C, Cuenca. Transcrita en: Gustavo Lloret, Museo de Las Conceptas un testimonio histórico (Cuenca: Fundación Museo de Las Conceptas, 2009), 19.

16. María Isabel Viforcos Marinas, "Luces y sombras de la vida monástica femenina: Las concepcionistas de Cuenca (Ecuador) en el siglo XVIII," Revista Estudios Humanísticos: geografía, historia, arte, no. 17 (1995): 312.

17. "Reglas de las religiosas de la Pura y Limpia Concepción," Revista del Archivo Nacional de Historia, sección Azuay, no. 7 (1987): 146-249. En el caso de las religiosas carmelitas el número máximo de monjas era de 21.

18. 1781, lib.6, f. 66-66v, ANH/C, Cuenca. 
de niñas fuera contraria a la regla por la falta de paz y sosiego que producían, así como por las indicaciones del Concilio de Trento que trataba de impedir que se forzase física o moralmente el ingreso a los monasterios. Quizás la falta de centros educativos o el desamparo en vida mundana ante la inexistencia de un familiar que les proporcionara protección, llegó a ser la razón que podría explicar que algunas monjas otorgaran donaciones a las niñas; tal es el caso de la religiosa María de San Nicolás, que solicita al obispo licencia para donar cuatrocientos pesos a la niña María Josefa en $1752^{19}$.

Conviene señalar también, que este aumento poblacional fue acompañado de un crecimiento económico ${ }^{20}$, con periodos más favorables que otros, pues el ingreso de las monjas venía acompañado de la dote, además de las donaciones, limosnas, legados píos, patronos, censos o capellanías que aportaron a la adquisición de tierras, adecuaciones, obras o ajuares. La dote, como instrumento articulador en las relaciones de poder, constituía una importante fuente de ingresos, tanto en efectivo como en bienes. A modo de ejemplo, religiosas concepcionistas como María de la Encarnación, en el pasado María Izquierdo del Prado, ingresa al monasterio como monja de velo negro en 1705 con un recibo de dote de 1500 pesos ${ }^{21}, 600$ pagados al contado y lo restante cargado a censo a su abuela y tío sobre unas casas y una renta anual de 40 pesos.

Una etapa de auge del monasterio cuencano, la encontramos durante la primera mitad del siglo XVIII, debida asimismo a la buena gestión de abadesas como Sebastiana de San Juan, que terminó la construcción de la iglesia (Fig. 3) y la ampliación del monasterio, ocupando toda una manzana. Las donaciones inter vivos o testamentarias, las cofradías y las festividades que impulsan sobre todo las religiosas, nos permiten constatar las advocaciones, mobiliarios y objetos artísticos con los que contaban. Por ejemplo, en la escritura de donación de todos sus bienes después de su deceso, Andrea Isabel de San Pablo, vecina de Guayaquil y religiosa novicia en el monasterio, afirma tener una celda y cocina de su propiedad, en la que ha realizado una refacción por 150 pesos, imponiendo a su futura compradora una misa anual cantada para el culto del patrocinio del patriarca san José de la iglesia de este monasterio. Además, ordena que un par de baúles, una cama, una paila, ropa blanca, dos olleras, un almirez y demás trastos mujeriles los perciba su negra esclava menor de edad Clara Gutiérrez, del mismo

19. $1752,5-9$, AHMC/C, Cuenca.

20. En el estudio realizado por el historiador Juan Chacón, se indica que en el periodo de la abadesa Sebastiana de San Juan (1712-1720), el monasterio disponía de 137.441 pesos que producían una renta anual de 6.872,3 pesos. Juan Chacón Zhapán, Historia del Corregimiento de Cuenca, 1557-1777 (Quito: Editorial del Banco Central del Ecuador, 1990), 470-481.

21. 1705, lib. 609, fol. 270, ANH/C, Cuenca. 


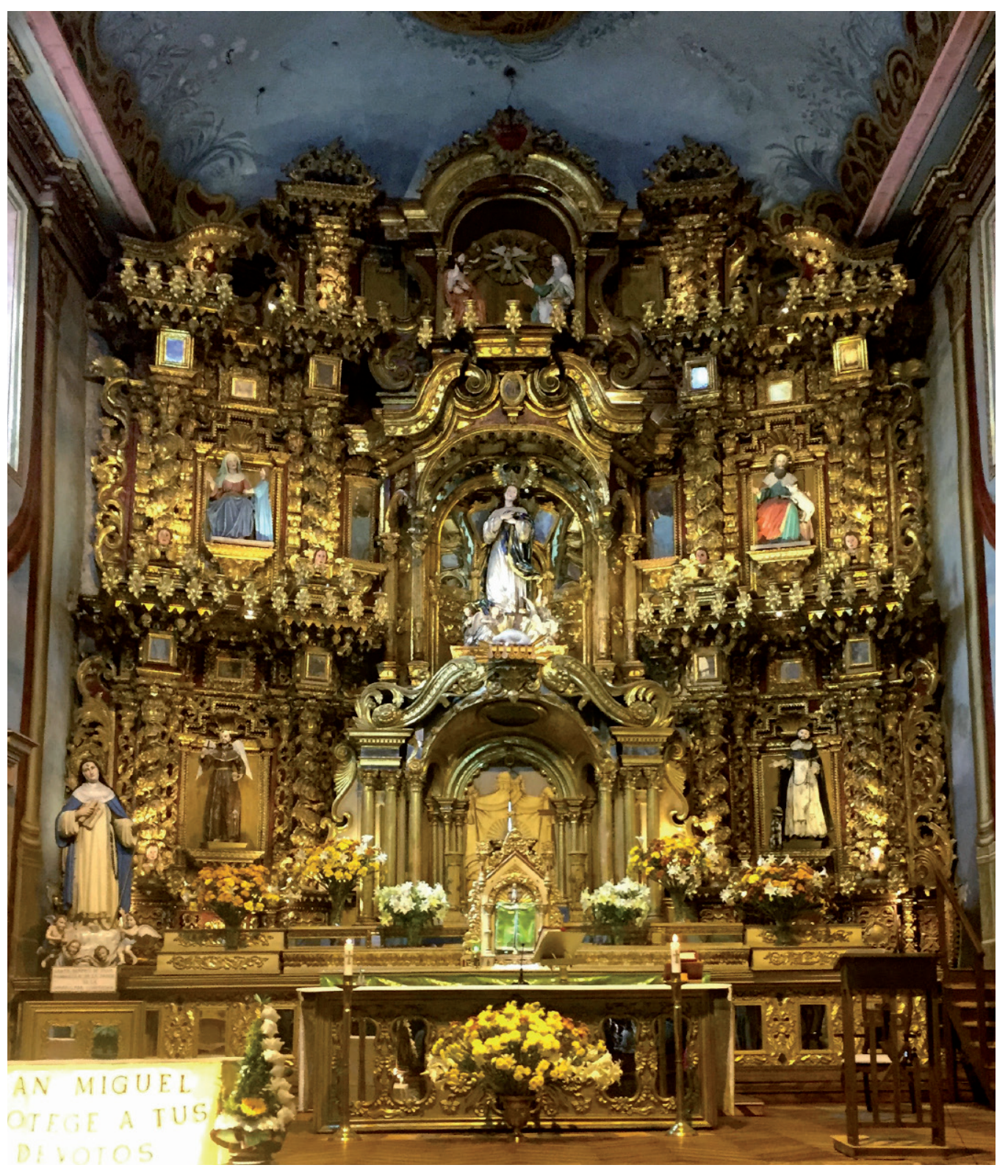

Fig. 3. Capilla mayor de la iglesia del monasterio de Las Conceptas, Cuenca.

(Fotografía de los autores).

modo que otros bienes como un rosario, relicario, alfombras, losa [sic ] de la China, seis vasos de cristal, una urna con el Niño Jesús con seis potencias de oro, diez láminas con un crucifijo, sean entregados para adornos de la celda de la religiosa María Ignacia de la Encarnación ${ }^{22}$.

Dichas riquezas artísticas se ven aumentadas con el impulso de las cofradías y capellanías. A diferencia de otras partes del virreinato peruano, en Cuenca no existieron hermandades de carácter artesanal, sino que cumplían más bien labores de tipo asistencial o de salvación. Cabe destacar la dedicada a la Asunción, vinculada a la iglesia matriz, la de Copacabana, asociada al hospital de la ciudad, la de la Santa Vera Cruz, ubicada en la iglesia

22. 1796 , lib. 557 , fol. $176 \mathrm{~V}$, ANH/C, Cuenca.

atrio Revista de Historia del Arte, ํㅡ 26 (2020): 88 - 118

elSSN: 2659-5230. https://doi.org/10.46661/atrio.5096 
de San Francisco, o la de San Lorenzo en la parroquia de San Sebastián. La iglesia de Las Conceptas también albergó algunas cofradías. En 1639 se funda la del Escapulario de la Limpia Concepción por las reverendas María de San José y Juana de San Nicolás; años más tarde, la cofradía del Santísimo Sacramento. Estas hermandades se sostenían con las obligaciones de los cofrades de contribuir con dinero desde su ingreso por el asiento en el libro, la celebración de misas y los gastos solemnes de las fiestas, además de las limosnas. El culto a las imágenes veneradas suscitó la adquisición de elementos pictóricos, escultóricos y textiles, amén de mobiliario para sus capillas. Dentro del contexto temporal de nuestro estudio, merece especial atención la devoción a Nuestra Señora de la Huida de Egipto, Nuestra Señora de Loreto, Señor del Coro y Arcángel San Miguel.

El monasterio concepcionista definido como institución perteneciente a una orden religiosa dedicada a la vida contemplativa y de clausura, empezó su vida en Cuenca adoptando como medio el culto y la fiesta a la Inmaculada Concepción. Esto no es una novedad para una comunidad de este tipo, pues la veneración a la Virgen estaba asociada con los símbolos de lo femenino, lo íntegro y lo ejemplar ${ }^{23}$. También desde su establecimiento la fiesta principal de la iglesia cuencana era la del Corpus Christi a costear por los caballeros capitulares, gremios y cofradías, estando íntimamente ligada a su accionar como demuestra que un año después el cabildo acuerda que "en la fiesta que ha de hacer de la octavación del Corpus Christi, el jueves por la mañana, el dicho monasterio haga y ha de hacer la fiesta"24. Tales celebraciones suponían grandes gastos en ornamentos como espejos, telas y demás enseres para su aderezo, además de cera y otros lujos, propios para el culto religioso, por lo que algunos ciudadanos imponían a censo un dinero para su buen desarrollo. Es el caso de Manuel Vélez e Isabel de Orellana, quienes fundan un censo de 300 pesos, impuestos en una estancia en Monay, en favor de la fiesta del Santísimo Sacramento en 1719. A través de una escritura de censo de 1734 conocemos que otra de las fiestas celebradas en el monasterio era la dedicada a Nuestra Señora de Copacabana, a la que Teresa de Barreto y Rafael Idrovo favorecen con cincuenta pesos ${ }^{25}$ a favor de Francisca de San Julián.

Otros son los censos para las fiestas impuestos por las mismas religiosas. En el archivo del monasterio encontramos algunos documentos en los que las financian a título

23. A este respecto, es necesario indicar el aporte que supuso a la mariología la concepción de la Inmaculada Eucarística en el arte colonial quiteño, devoción que fusiona dos de las principales festividades católicas, la fiesta de la Inmaculada Concepción y el Corpus Christi.

24. Deborah L. Truhan y Luz María Guapizaca Vargas, Libro de Cabildos de la ciudad de Cuenca, 1597-1603 (Cuenca: Casa de la Cultura Ecuatoriana Benjamín Carrión y Alcaldía de Cuenca, 2010), 381.

25. 1751, 3-112, AHMC/C, Cuenca. 
personal. Por ejemplo, Luisa de Santa Rosa imponía a censo, en 1745, mil pesos anuales para dotar con sus réditos a la fiesta del arcángel San Miguel ${ }^{26}$. Seis años más tarde, siendo ya abadesa, solicita licencia para realizar estas fiestas ${ }^{27}$. Otro caso es el de Francisca San Marcial, profesa en 1705, que establece se vendan unas tiendas de su propiedad y se imponga un censo perpetuo a favor de las fiestas del Sagrado Corazón ${ }^{28}$ y de sus cuatro criadas.

A nivel local, aparte de la ya señalada fiesta del Corpus Christi, cabe indicar dos advocaciones marianas en los meses de mayo y septiembre, que históricamente revestían gran pompa y fervor, dotando el municipio partidas específicas para tales festividades. Estas son el día de santa Ana, patrona de la ciudad, y el día de la Virgen de la Merced, sobre todo a partir de la presencia de los miembros de la orden mercedaria en la ciudad de Cuenca. Cabe indicar, que los mercedarios se establecen en Cuenca en 1712 y fundan su iglesia y convento en los límites de la traza urbana colonial, cercanos al monasterio de Las Conceptas. Después de ciento cincuenta años, junto con franciscanos y agustinos abandonan la ciudad por un lapso de tiempo, quedando la curia diocesana en un inicio, a cargo del primigenio convento de La Merced de Cuenca y de todos sus bienes ${ }^{29}$.

\section{La pintura de la Virgen de la Merced del Museo de Las Conceptas de Cuenca}

Las claves contextuales esgrimidas con anterioridad resultan imprescindibles para abordar el estudio de la pintura de referencia. En realidad, se trata de uno de los grandes atractivos del Museo de Las Conceptas de Cuenca (Fig. 4), a tenor no solo de la calidad de la obra sino también del componente de género que entraña merced a su autoría y la fecha ciertamente temprana en que se realiza, conforme a los escasos testimonios conservados de este tipo en la antigua Audiencia de Quito ${ }^{30}$. Dispuesta en la sala de temática mariana, en la planta alta del museo, la Virgen de la Merced se revela como una pieza que, pese a la inscripción localizada en un escabel nuboso de la franja inferior, continúa despertando diferentes incógnitas relativas a su origen, factura e, incluso, destino.

\footnotetext{
26. $1745,1-51, A H M C / C$, Cuenca.

27. $1751,1-53, A H M C / C$, Cuenca. Esta fiesta a día de hoy representa una de las advocaciones más arraigadas dentro y fuera del monasterio.

28. 1756, 1-14, AHMC/C, Cuenca.

29. Posteriormente pasa a la administración de la comunidad de Padres Oblatos. A su regreso a la ciudad de Cuenca en 1938 no se ubicaron en su antiguo cenobio sino en el barrio de San José de El Vecino, donde edificaron un nuevo convento.

30. José Carlos Arias Álvarez, Evidente y oculto: viaje por la iconografía del arte colonial ecuatoriano (Guayaquil: Banco Central de Ecuador, 2008).
} 


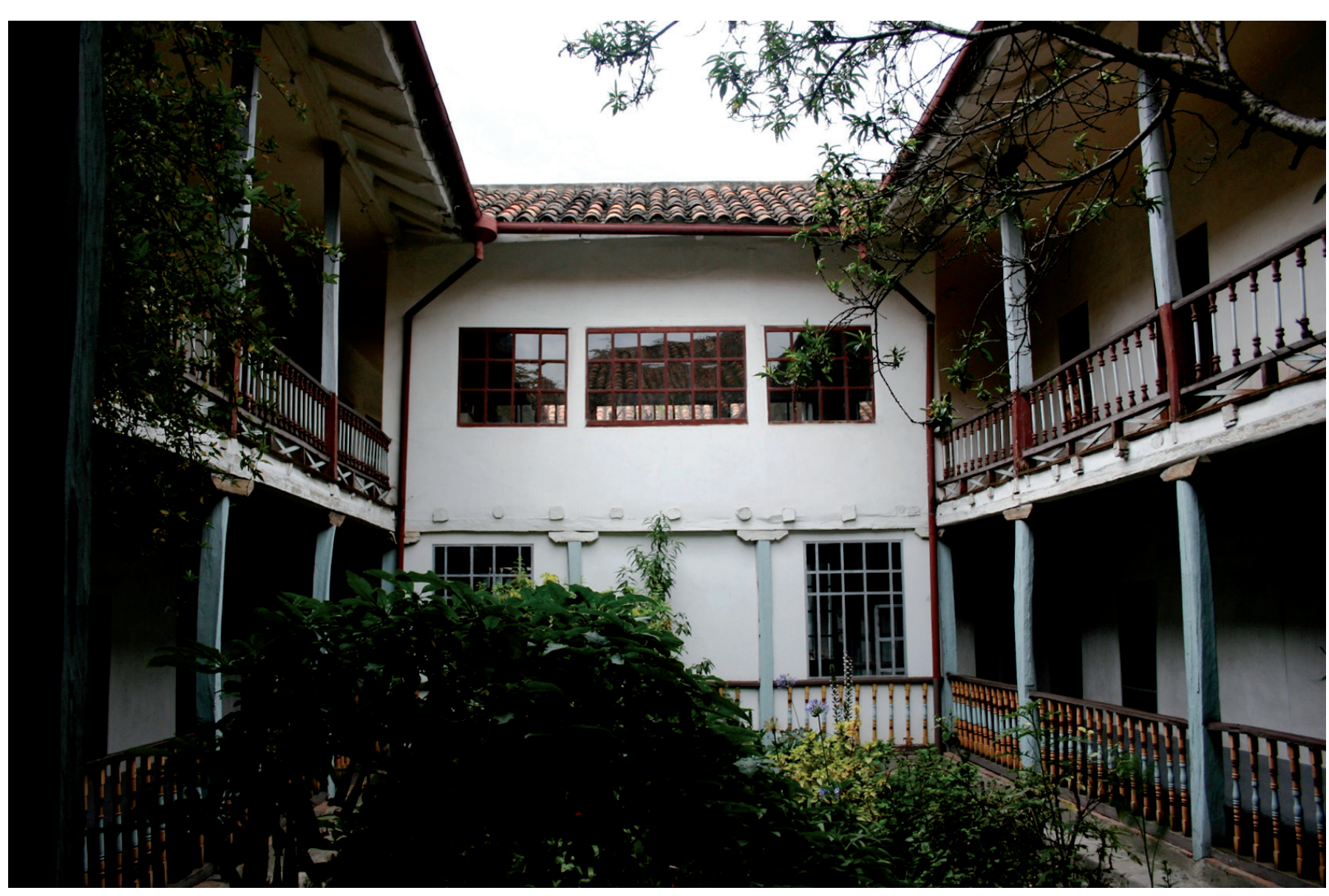

Fig. 4. Interior del monasterio de Las Conceptas de Cuenca, zona del antiguo hospital que hoy ocupa el museo. (Fotografía de los autores).

En efecto, será la leyenda del lienzo el único testimonio que poseemos para evaluar su historia, más allá del depósito en el monasterio de Las Conceptas desde tiempo atrás. Decimos que "desde tiempo atrás" porque tampoco queda del todo claro que fuera efectuada para dicha institución y allí depositada desde un primer momento, tal como iremos desgranando a continuación. En este sentido, las dudas referentes a los datos de los que disponemos pueden llevarnos a pensar en opciones complementarias, bien como obra proveniente de otro monasterio de la ciudad o fuera de ella, bien como fruto de una donación de carácter particular a las monjas concepcionistas formalizada en una fecha sin determinar.

Sea como fuere, es necesario acudir a la fuente única y principal de información, la inscripción de la base de la pintura, para así poder examinar los aspectos proporcionados: "YO S. A MARÍA DE LA MERCED YSE ESTA OBRA EL AÑO DE 1751". Partimos de la premisa de que esta zona del lienzo, al igual que el resto, presenta lagunas en la capa pictórica y repintes que dificultan en parte su lectura, cuestión por la que requiere de una importante intervención restauradora antes de que se produzca un mayor avance del deterioro. Aun así, estamos en disposición de transcribir correctamente el texto, sumido durante 


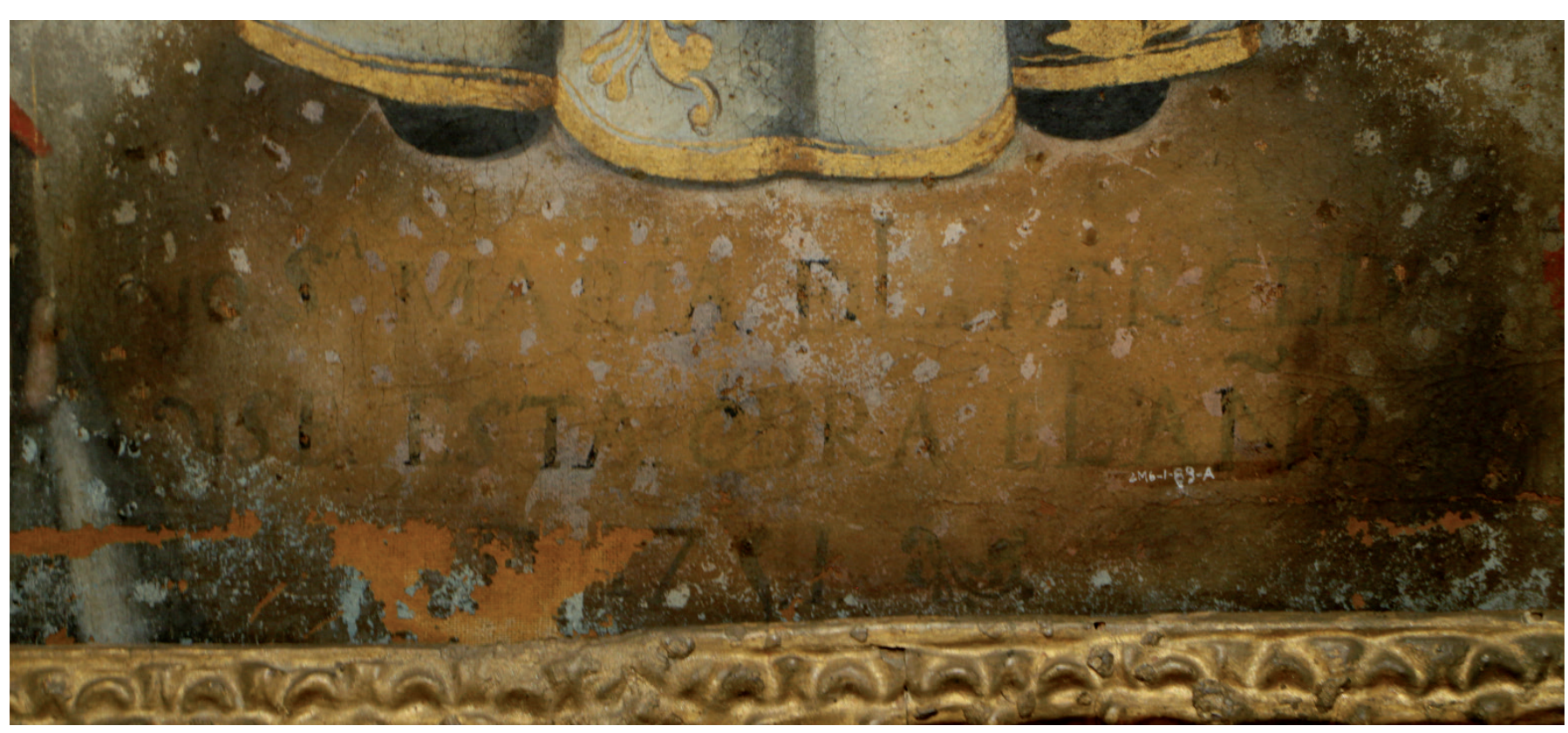

Fig. 5. Leyenda sobre escabel de nubes, en la parte inferior de la pintura, donde se marca el nombre de la autora y la fecha de su hechura. (Fotografía de los autores).

tiempo en parciales disquisiciones. Comencemos por la cuestión de carácter cronológico concerniente a la factura de la obra. Hasta la presente investigación se apostó siempre por datarla en 1781, tal como aparece reseñado en la cédula del mismo museo y en otras publicaciones que han aludido a esta, siempre desde una visión superficial (Fig. 5).

Pues bien, las dudas que despertaban en nosotros algunos de los dígitos, en concreto el tercero de ellos, fueron despejadas al consultar a paleógrafos y archiveros, tanto ecuatorianos como españoles, quienes coincidieron todos en aquello que ya sospechábamos. En otras palabras, que ese tercer número no era un 8 , como se pensaba, sino más bien un 5, lo que cambió en esencia el panorama al tener que adelantar treinta años la franja temporal de la investigación. Cierto es que el trazo especialmente sinuoso del número 5 confundió a quienes se enfrentaron con su reproducción, si bien el hecho de que quedara perfectamente rematado en el extremo bajo y no tuviera continuidad hacia arriba imposibilita de manera definitiva la primera disyuntiva.

Sobre la fecha fijada y alrededor de las décadas centrales del siglo XVIII ha girado nuestra investigación en los documentos del archivo histórico del monasterio de Las Conceptas de Cuenca, con vistas a indagar acerca de la monja que firma como autora de la pintura. Un estado, el religioso, que se deduce de su propio nombre, María de la Merced, desde el momento inicial centro del examen de los listados y relaciones que se generaron en la documentación de la época, en torno a los ingresos, profesiones, capítulos, fallecimientos e informaciones varias. Habría que considerar antes de nada que 
los fondos del archivo conventual son bastante completos y no han sufrido pérdidas importantes a lo largo del tiempo. Pese a ello, y después de haber repasado de manera concienzuda los legajos del periodo en el que pudo vivir dicha religiosa, no hemos encontrado coincidencia alguna entre los nombres. En el arco cronológico comprendido entre 1700 y 1770 aparecen reflejadas hasta cinco componentes de la comunidad concepcionista llamadas María, aunque ninguna concuerda con la que nos atañe: María Natividad, María Ignacia de la Encarnación, María Noroña, María San Francisco y María de San Nicolás.

Esto nos lleva a dudar sobre la pertenencia de María de la Merced al monasterio de Las Conceptas de Cuenca, aunque es un dilema que no puede darse por cerrado a no ser que aparezca nueva documentación que lo certifique. Incluso hemos llegado a plantearnos la posibilidad de que fuera una pintora laica, muy poco probable por el tipo de nombre utilizado y el modo en el que firma. En este sentido, queda constancia de la labor desarrollada en Cuenca a principios del siglo XVIII por la conocida como "María la pintora", de la que solo sabemos que estaba activa en 1720 y se le incluye en un testimonio acerca de linderos de tierras ${ }^{31}$. Algo lejos queda esta hipótesis si se considera además el tratamiento recibido en la inscripción del lienzo antes del nombre. La abreviatura "S." responde sin duda alguna al calificativo de sor, esto es, hermana de una comunidad conventual; cuestión, la del vínculo del estado religioso con el desempeño artístico, bastante habitual tanto en Europa como en Hispanoamérica durante la Edad Moderna. Sin embargo, la colocación de otra letra elevada por encima de la "S" no ha sabido interpretarse como debiera, propiciando errores de transcripción. Tradicionalmente se ha querido descifrar como la " $R$ " que finaliza la palabra sor, si bien no existe aquí una palpable conexión al resultar evidente que se trata de una " $A$ " mayúscula. Aún más, la pintora quiso separar de manera intencionada ambas letras con un punto, de modo que pasan a abreviar palabras distintas. La primera, como hemos subrayado, el tratamiento de sor; la segunda, con toda seguridad, una primera parte de un nombre compuesto, tal vez Ana, que no pudo desarrollar por falta de espacio o por no considerarlo del todo significativo en su identificación habitual.

Una vez examinados, por partes, los datos que suministra la leyenda del lienzo continúa quedando en el aire la institución a la que perteneció y la casa en la que vivió la monja pintora. Cierto es que tanto la temática representada como el nombre religioso de la autora

31. Jesús Paniagua Pérez y Deborah L. Truhan, Oficios y actividad paragremial en la Real Audiencia de Quito (1557-1730). El corregimiento de Cuenca (León: Universidad, 2003), 220-221. 
invitan a pensar en lazos directos con la orden mercedaria. Por un lado, es de generalizado conocimiento el celo de las diferentes órdenes religiosas por difundir en exclusividad sus temas, advocaciones y personajes más relevantes a modo de básicos canales proselitistas. Pero esta sería una argumentación en extremo simplista, según comprobaremos a continuación, por las especiales circunstancias devocionales del lugar, con reflejo en las representaciones artísticas. En el caso de haber pertenecido a la orden fundada por san Pedro Nolasco tendría que haber habitado en un convento fuera de Cuenca, o bien en un beaterio de la misma religión como el existente en Quito ${ }^{32}$. Como ya indicamos con anterioridad, dos eran las órdenes religiosas femeninas asentadas en la ciudad para nuestra época de estudio, concepcionista y carmelita. La orden mercedaria establece para 1712 su convento masculino en la ciudad, y en Quito se encontraba activo desde 1727 el beaterio mercedario, como casa de recogimiento bajo la tutela del fraile cuencano Gaspar Lozano ${ }^{33}$.

Este es, precisamente, uno de los puntos clave a tener presente en el estudio de la pintura, por cuanto el culto a la Virgen de la Merced o de las Mercedes gozó y sigue gozando de enorme proyección no solo en Cuenca, ni en todo el Ecuador, sino también en otros países de la América hispana ${ }^{34}$. Lo que quiere decir que no es de extrañar tampoco que esta representación mariana emparentada con la orden mercedaria se hiciera para el monasterio concepcionista, ni que la religiosa pintora, caso de pertenecer a su comunidad, utilizara dicho título en su nombre dentro de la clausura. Para una mejor comprensión del asunto nada mejor que ahondar en las raíces del tradicional culto a la Virgen de la Merced en tierras del virreinato peruano. El vínculo surge en paralelo a la fundación de Quito en 1534 de la mano del capitán Sebastián de Benalcázar, quien llevaba como capellán al mercedario fray Hernando de Granada. Desde luego un buen inicio para que poco después, en 1537, el mismo religioso estableciera un convento de la orden en la ciudad, en el cual se veneró desde el inicio una escultura de la Virgen de la Merced expresamente donada por el emperador Carlos V 35 .

Numerosos portentos y milagros acaecidos por su intercesión despertaron un enorme fervor entre los pobladores de Quito encargados de expandirlo por toda su audiencia,

32. Alfonso Ortiz Crespo, Ciudad de Quito. Guía de arquitectura (Quito: Municipio de Quito; Sevilla: Embajada de España, 2004), 2: $37-38$.

33. En el año de 1736 este beaterio obtiene la autorización para vivir en clausura perpetua y comunidad, y es administrado por la orden de la Merced hasta 1786.

34. Jesús Paniagua Pérez, "Iconografía mercedaria en la colección Crespi de Cuenca (Ecuador)," Estudios, no. 192 (1996): 35-55; Magdalena Gallegos de Donoso, Iconografía de la Virgen María en el Arte ecuatoriano (Quito: Museo Banco Central del Ecuador, 1982); Ángel Justo Estebaranz, "Advocaciones marianas españolas en el arte de la Real Audiencia de Quito," Atrio. Revista de Historia del Arte, no. 20 (2014): 24-39.

35. Julio Matovelle, Historia del culto a Nuestra Señora de las Mercedes en la República del Ecuador (Quito: Tipografía Salesiana, 1910), 1-2. 
haciendo saber las maravillas que llegó a posibilitar y difundiendo pinturas de la misma imagen. Se le llegó a conocer también como Virgen de los Terremotos, al ser solicitada su intercesión en el acaecido en 1575, y Virgen Peregrina por las numerosas procesiones, rogativas y romerías en las que participaba ${ }^{36}$. Así es como fue tomando popularidad la escultura quiteña y la advocación de la Virgen de la Merced, hasta el punto de que a partir de 1703 experimentó una mayor propagación al calor de la reedificación de su templo. Con vistas a recaudar fondos para la obra los frailes decidieron solicitar limosnas por buena parte del sur de América, portando con ellos la efigie de la Virgen de la Merced convertida en protagonista de todo tipo de prodigios. Por tanto, el inicio del siglo XVIII supondría un verdadero impulso, que pronto enraizó en otras poblaciones de la circunscripción. Entre ellas, en Cuenca donde, además, los mercedarios se establecen definitivamente en 1759 después de varias décadas de tentativas, idas y venidas, y una primera toma de posesión de los solares y asiento en $1713^{37}$. Tanto éxito alcanzó en el tiempo que, en 1861, después del triunfo sobre las tropas invasoras del Perú, fue proclamada patrona y protectora de la República y del Ejército, mientras que en 1963 un decreto ejecutivo la nombraba generalísima de las Fuerzas Armadas ${ }^{38}$.

Visto lo anterior no es de extrañar la profusión de testimonios artísticos plásticos acerca de la Virgen de la Merced en distintos edificios de Cuenca, tanto de carácter religioso como civil. También en el monasterio de Las Conceptas, donde existen tres pinturas y una escultura sobre el tema. En la clausura, concretamente en uno de los laterales del refectorio, se localiza una pintura mural con la representación de la Virgen de la Merced (siglo XVIII), cuya disposición asentada en una peana y libre de todo contexto, salvo unos cortinajes que la enmarcan, manifiesta el reflejo o retrato de una imagen escultórica, con bastante seguridad La Peregrina de Quito a pesar de mostrarse erguida ${ }^{39}$. Una obra, dicho sea de paso, atribuida al pintor Joan de Orellana ${ }^{40}$. En el Museo, y aparte de la reducida escultura dieciochesca en madera tallada, policromada y estofada, encontramos un lienzo de la misma temática con la Virgen entronizada ante un fondo neutro, original del siglo XVIII

36. Juan Cordero Íñiguez, María en las artes cuencanas (Cuenca: Universidad de Cuenca, 2004), 24; Juan Martínez Borrero, Carmen Ugalde de Valdivieso, y Juan Cordero Íñiguez, De lo divino y lo profano. Arte cuencano de los siglos XVIII y XIX (Cuenca: Ediciones del Banco Central del Ecuador, 1997), 114.

37. Juan Cordero Íñiguez, Historia de Cuenca y su región. Segunda parte, vol. 5 de Creación y desenvolvimiento de la gobernación (1777-1809) (Cuenca: Universidad-Municipalidad, 2016), 186-190; José María Vargas, El arte religioso en Cuenca (Quito: Editorial Santo Domingo, 1967), 19.

38. José Brunet, "La Virgen de la Merced y sus diversos patronazgos en América," Estudios, no. 172-175 (1991): 307-488.

39. Jesús Paniagua Pérez, "Las pinturas murales del convento de la Concepción de Cuenca (Ecuador)," Cuadernos de Arte Colonial, no. 7 (1991): 114-118; Juan Martínez Borrero, La pintura popular del Carmen. Identidad y cultura en el siglo XVIII (Cuenca: CIDAP, 1983), 104.

40. Cordero Îniguez, Historia de Cuenca, 222. 


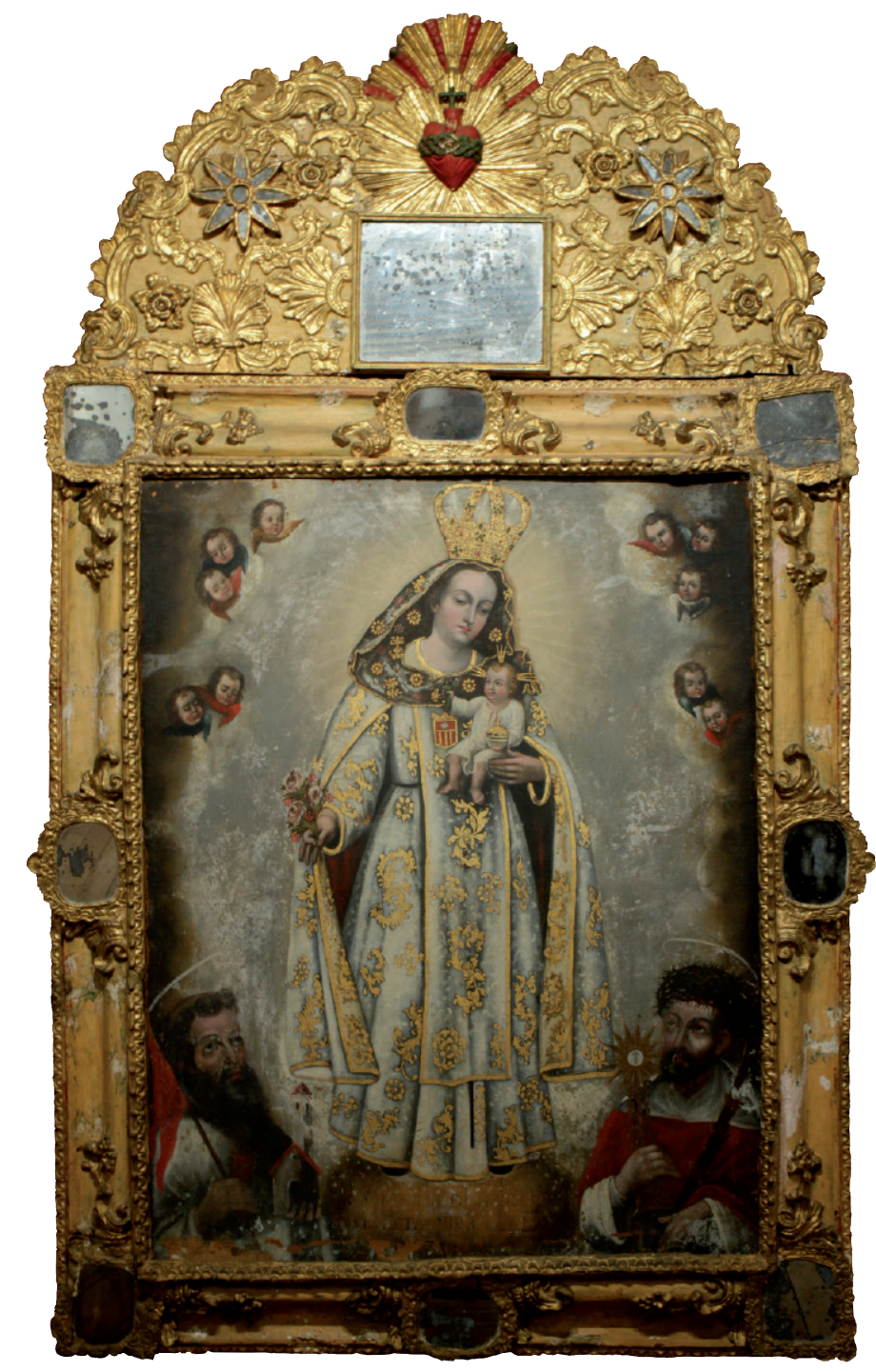

Fig. 6. Sor María de la Merced, Virgen de la Merced, 1751. Óleo sobre lienzo, $195 \times 122$ cm. Museo de Las Conceptas, Cuenca. (Fotografía de los autores). aunque ampliamente repintado en el $\mathrm{XIX}$, perdiendo de esta manera sus calidades artísticas (Fig. 6).

La nómina queda completada con el lienzo objeto de estudio, en realidad una representación de la Virgen de la Merced con tintes alegóricos y propagandísticos, dentro de los modelos ampliamente difundidos por la orden mercedaria ${ }^{41}$. La pintora encuentra en esta la esencia barroca recreando el espacio del milagro a partir de un amplio rompimiento de gloria, en el que la penumbra de las formaciones nubosas con cabezas de querubines, en el contorno, sirven de contraste a la potente iluminación medular de refulgentes rayos alrededor de la figura mariana. Queda claro, por tanto, que se busca centrar la atención del espectador en las imágenes al utilizar la eliminación de lo superfluo, de ahí que entrañe asimismo un carác-

ter piadoso o devoto. Y lo hace, además, trazando líneas compositivas concéntricas desde el perímetro y hacia el rostro de la Virgen dirigidas a través de los gestos y miradas del Niño Jesús, los santos de la base y los querubines, algunos de estos últimos intentando al mismo tiempo implicar directamente al que lo contempla con su vista frontal. Se trata de una pintura de contrastes, como ya avanzamos, siempre dependiente de particularidades propias del arte colonial, aquí especialmente adscrito al foco de atracción artístico dependiente de Quito. Desde el diferente tratamiento de los volúmenes, más naturalistas en las carnaciones frente a la planitud y acartonamiento de las vestimentas, a la utilización de colores vivos y llamativos en conjunción con los dorados que simulan

41. Eulalia Moreno de Dávila, La colección pictórica del Museo de las Conceptas de Cuenca (Cuenca: Universidad del Azuay, 2005), 107-108; José María Vargas, Patrimonio artístico ecuatoriano (Quito: Trama Ediciones, 2005), 393; Rodrigo López Monsalve, Cuenca, Patrimonio Cultural de la Humanidad (Cuenca: s. e., 2003), 58; Alexandra Kennedy Troya, "Mujeres en los claustros: artistas, mecenas y coleccionistas," en Arte de la Real Audiencia de Quito, siglos XVII-XIX. Patronos, comportamientos y comunidades (San Sebastián: Nerea, 2002), 127. 
metales preciosos (en corona, potencias, custodia y globo terráqueo), así como bordados vegetales y florales en el velo, manto, túnica y escapulario de la Virgen, y los ribeteados de los ropajes. Sin desdeñar, los habituales defectos perspectívicos derivados de los detalles mencionados.

Cierto es que los rostros de los personajes exponen unos rasgos estereotipados que poco difieren entre los de un santo y el otro, o bien entre el del Niño Jesús y los querubines. No obstante, alcanza una mayor distinción en el de la Virgen María, desde el mismo momento en que propone un semblante tocado por las sombras que genera el velo oscuro de transpa-

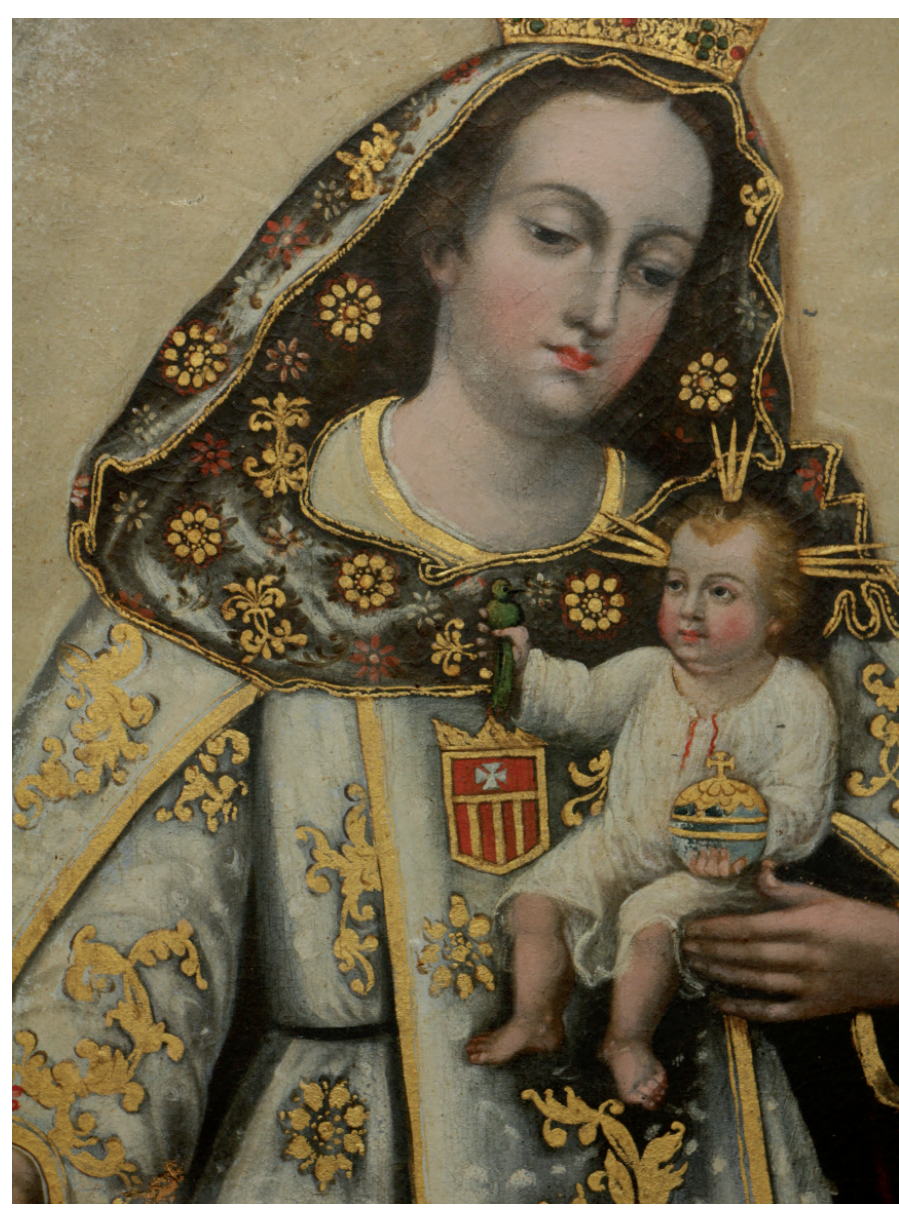

Fig. 7. Detalle de la Virgen con el Niño Jesús en la pintura del Museo de Las Conceptas, Cuenca. (Fotografía de los autores). rencias, unido a la vida y calidez de los pómulos sonrosados. Las redondeces en las facciones imprimen un alto grado de dulzura afín al gesto de silente interacción con el Niño, para lo cual genera una acusada inclinación de la cabeza, cuyos ojos dejan caer los párpados con vistas a que su mirada se encuentre solo con la del infante varón. En definitiva, una composición equilibrada, de esquema triangular y naturaleza introspectiva, que invita a la reflexión y al rezo desde la afabilidad y el ambiente místico (Fig. 7).

Desde el punto de vista iconográfico, el lienzo del Museo de Las Conceptas de Cuenca repite un modelo que se traslada desde Europa a Hispanoamérica, a partir de grabados y reproducciones pictóricas, y que alcanza una enorme proyección en el lugar durante los siglos XVIII y XIX. A saber, la tipología conocida como Virgen en Gloria rodeada de ángeles y en calidad de intercesora, teniendo su primitiva fuente iconográfica en los grabados de fray Isidro de Valcázar ${ }^{42}$. En efecto, un esquema de armónicas y jerarquizadas directrices, donde el universo mercedario queda definido por la figura central de la Virgen de la Merced

42. Vicent Zuriaga Senent, La imagen devocional en la Orden de Nuestra Señora de la Merced. Tradición, formación, continuidad y variantes (Valencia: Servicio de Publicaciones, 2005), 238-239. 
jalonada a sus pies por san Pedro Nolasco y san Ramón Nonato. Como decíamos, una representación con numerosos precedentes en el arte español de la Edad Moderna, caso de la pintura de Santiago Morán sobre la Aparición de la Virgen de la Merced a San Ramón Nonato y San Pedro Nolasco (1656) de la capilla del Cristo de Rivas de Jarama (Madrid) o la Virgen de la Merced (anónimo, siglo XVIII) conservada en el Archivo Histórico de El Puig (Valencia), entre otras ${ }^{43}$. Sin olvidar, la magistral obra de Francisco de Zurbarán (h. 1635-1640) depositada en la colección Huarte Myers de Pamplona ${ }^{44}$.

En su expansión por el continente americano la figura de la Virgen asumió diversas variantes, a pesar de que hay una que es la que más se repite. Nos referimos a la representación de la Virgen de la Merced erguida, desprovista del Niño Jesús y desplegando el manto en calidad de protectora o Eleusa, bien recogido por ángeles bien sustentado en los brazos que se desplazan lateralmente. La imagen mariana porta en las manos el cetro de la realeza divina, aunque lo más habitual es que acuda a símbolos y elementos propios de la orden tales como el escapulario mercedario, intercesor y devocional, y los grilletes alegóricos acerca de la función principal de la orden como redentora de cautivos cristianos. Bajo el manto acoge a san Pedro Nolasco y san Ramón Nonato, distinguidos con sus atributos, aun cuando existen versiones en las que se suman otros personajes como religiosos y religiosas de esta orden, prisioneros redimidos y donantes.

Debe considerarse, antes de nada, que dicha iconografía no es más que una interpretación de la tradicional Virgen de la Misericordia, que tuvo origen en la Baja Edad Media y se consolidó con posterioridad en las manifestaciones pictóricas y escultóricas del Renacimiento y el Barroco. Desde luego, siempre influida en su difusión artística por el grabado inserto en el Speculum Fratrum (1533) de Nadal Gaver. Además, se revela como el modelo iconográfico más antiguo utilizado, siempre en relación con la humanidad de redimir cautivos cristianos. De los muchos ejemplos adaptados a la advocación mariana de la Merced en Hispanoamérica pueden reseñarse los de la colección de Iván Cruz Cevallos de Quito (anónimo, siglo XVIII)45, Museo de Bellas Artes de Talca en Chile (José Gil de Castro, 1814-1817), Museo de la Merced de Santiago de Chile (uno anónimo cuzqueño, siglo XVIII y, otro, anónimo quiteño del siglo XIX $)^{46}$ o basílica de la Merced de

43. Francisco Cano Manrique, María Teresa Ruiz Barrera, y Juan Luis Ravé Prieto, La Orden de la Merced en Andalucía (1203-1603-2003). Patrimonio histórico mercedario, en la provincia de Sevilla (Sevilla: Junta de Andalucía, 2003).

44. María Teresa Ruiz Barrera, "Notas iconográficas sobre la Virgen de la Merced. Sus artes plásticas en Andalucía occidental," en Regina mater. Estudios históricos, artísticos y antropológicos de advocaciones marianas (Córdoba: Litopress, 2016), 569-588.

45. Suzanne L. Stratton-Pruitt, ed., El arte de la pintura en Ouito (Philadelphia: Saint Joseph's University Press, 2012).

46. Rolando Báez, "Marianismo y mestizaje en la cultura visual chilena. Una aproximación desde la práctica curatorial," en Vírgenes, mártires y santas mujeres (Santiago de Chile: Museo La Merced, 2014), 36-82. 
Yarumal en Colombia (anónimo, 1789). En otras ocasiones, se continúa una distribución similar de los personajes, pero la Virgen, aun alzada, omite los desplazamientos de brazos y manto para disponerse con el Niño Jesús en su regazo, caso de la obra del Museo de Artes Universidad de los Andes en Santiago de Chile (1800-1850) o, a modo de Inmaculada Concepción, en el lienzo del convento de la Merced de Cuzco (siglo XVIII).

La figura de la Virgen de la Merced del Museo de Las Conceptas de Cuenca está más cerca de estos últimos modelos, si bien con algunos motivos alegóricos distintivos. Esta proyecta las tradicionales vestimentas conforme al ajuste de la túnica, escapulario (con el escudo de la orden dotado de las armas reales de Aragón y la cruz insignia de la catedral de Barcelona) y la capa blanca (símbolo de la pura concepción de María) ${ }^{47}$, simulando ricas telas de brocados en la aplicación dorada de rosetas y formaciones vegetales de trazos sinuosos. El cetro es sustituido en la mano derecha por un ramillete de flores con rosas y otras especies autóctonas, motivos junto a las frutas ampliamente utilizados en el arte colonial de la Edad Moderna y que aquí encarnan los valores de pureza y dignidad de María a través del triunfo y renovación de la vida ${ }^{48}$.

Por su parte, el Niño Jesús ocupa sus manos con dos elementos simbólicos; de un lado, el tradicional globo terráqueo coronado con la cruz latina relativo a su calidad como "pequeño emperador" con dominio sobre todo el orbe cristiano. Más original resulta el otro motivo que enarbola con la mano derecha, un colibrí -en quichua quinde- de color verde singularizado como un ave autóctona a pesar de que participa del mensaje común utilizado en las representaciones del infante, cuando se le acompaña de otro tipo de aves. Es decir, un elemento emblemático trascendente y espiritual, en su relación con el aire, que en el plano de la rememoración pasionista remite directamente a la resurrección ${ }^{49}$. No obstante, y acudiendo a la siempre esclarecedora Teresa Gisbert, cabría remitir a las correspondencias de elementos que tanto ayudaron en la asimilación de ideas, dentro de los nuevos códigos de pensamiento que trataban de imponerse a la cultura indígena. La enorme y exótica variedad de aves del continente americano intensificaron esa visión de los pájaros como animales fantásticos, que poseían poderes sobrenaturales. Hasta el punto en que el cielo se consideró como un enorme jardín poblado de pájaros, donde se les equiparaba con las mismas figuras

47. Lisardo Guede, La Merced (compendio histórico, en 15 lecciones)(Málaga: Imprenta J. Ruiz, 1977), 22.

48. Olaya Sanfuentes Echeverría, "Las frutas en la pintura colonial de Chile: más que decoración, simbolismo," Ensayos. Historia y teoría del arte, no. 24 (2013): 84-100.

49. María Dolores-Carmen Morales Muñiz, "El simbolismo medieval en la cultura medieval," Espacio, Tiempo y Forma, serie III, no. 9 (1996): 229-255. 
angélicas. Un concepto asimilado pronto por los indígenas, sabedores de su desempeño en calidad de portadores de la voz de Dios. Sin desdeñar, en ningún momento, Ios lazos simbólicos que lo presentan como prefiguración del alma cristiana y signo evidente de inmortalidad ${ }^{50}$.

El rompimiento de gloria que inunda la totalidad de la pintura marca unos evidentes contrastes lumínicos entre la parte central -de refulgente irradiación- y el contorno perimetral, que va sumándose a la penumbra proporcionada por el celaje. Este último resulta precisamente el ambiente idóneo para hacer resaltar las cabezas de querubines aladas en grupos de dos y tres, cuyos gestos alternan el gozo y la pesadumbre al tiempo que incide en la conexión con el espectador a través de la mirada, implicándolo así en la escena. Más allá del consustancial componente divino que los ángeles y querubines transmiten en este tipo de pinturas, habría que considerar igualmente el sincretismo adoptado entre los indígenas en la difusión de doctrinas y representaciones religiosas. En otras palabras, el interés por sustituir la adoración hacia los astros y otros fenómenos astronómicos por figuras angélicas que unían lo celestial y terrenal y servían de verdaderos portavoces de la divinidad.

Las otras dos figuras que completan la representación, san Pedro Nolasco y san Ramón Nonato, se adaptan claramente a los modelos antes planteados al disponerse en los ángulos inferiores flanqueando a la imagen mariana, con una configuración de medio cuerpo y provistos de los atavíos y atributos más característicos ${ }^{51}$; sin desdeñar, en ningún momento, la distinción celestial de los personajes orlados con sus respectivos nimbos sobre la cabeza, lo que remite junto con su propia presencia inmediata a la Virgen a su calidad de verdaderos uomini famosi de la orden. San Pedro Nolasco repite la iconografía habitual al mostrarse ataviado con el hábito blanco y el escudo de Aragón al pecho, a complementar con la banderola o estandarte, que ratifica el emblema de su religión, y la maqueta arquitectónica de un edificio eclesiástico concerniente a su calidad de fundador (Figs. 8 y 9 ).

Por su parte, san Ramón Nonato registra una serie de atributos más variados referentes todos a hechos que le ocurrieron en vida. Vestido con la muceta púrpura cardenalicia sobre el hábito blanco, en este llama poderosamente la atención el candado con el que se cierra su boca, signo de la acción emprendida contra él por los musulmanes

50. Teresa Gisbert, El paraíso de los pájaros parlantes. La imagen del otro en la cultura andina (La Paz: Plural Editores, 1999), 152-154. 51. Cordero Íñiguez, Historia de Cuenca, 167. 
Fig. 8. El fundador de la orden mercedaria, san Pedro Nolasco, a los pies de la Virgen de la Merced. (Fotografía de los autores).

Fig. 9. San Ramón Nonato en la pintura del Museo de Las Conceptas. (Fotografía de los autores).
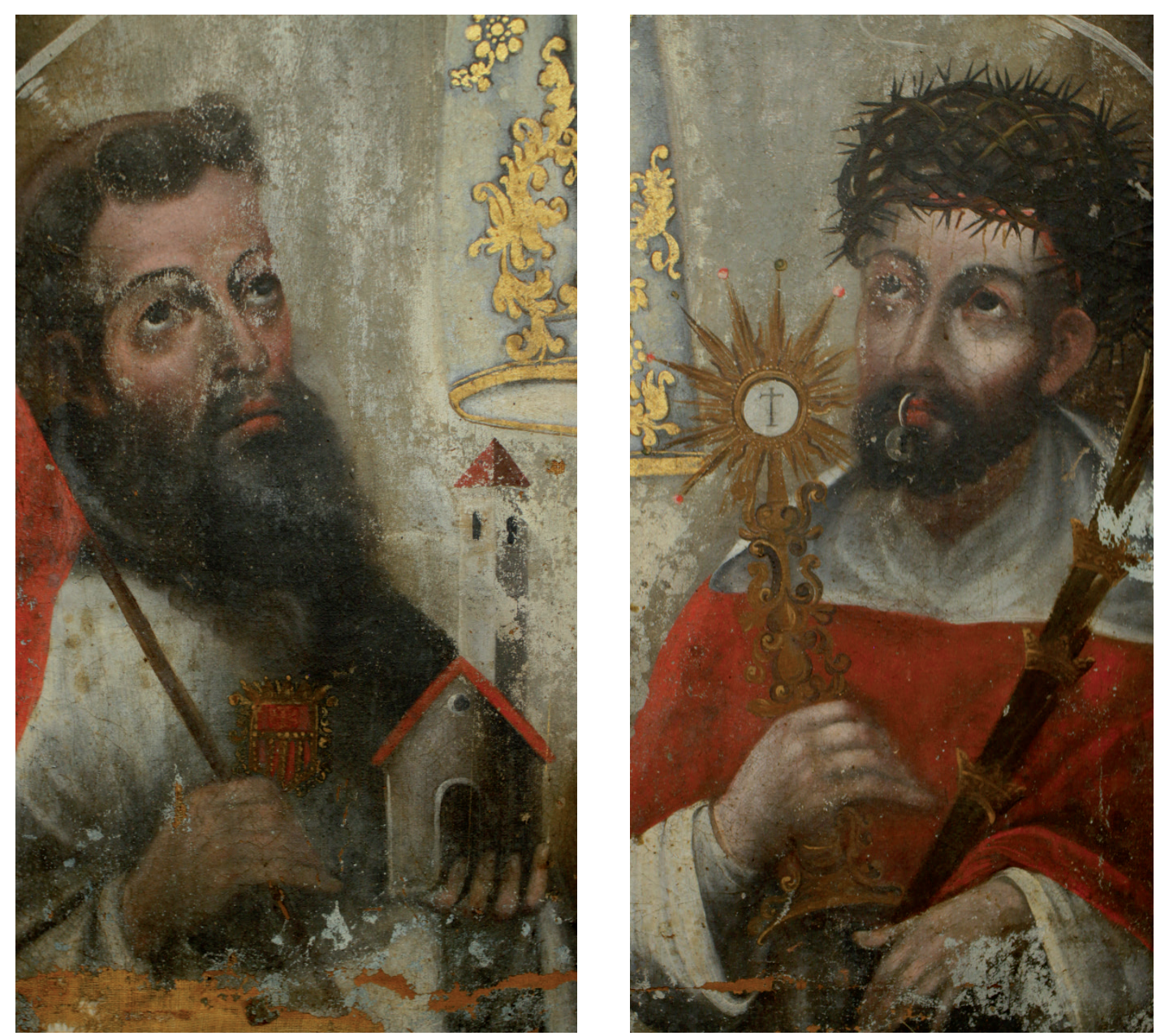

de Argel para que dejara de predicar en su viaje de 1203 a tierras norteafricanas. Resultado de su caridad y sencillez es la corona de espinas que porta sobre la cabeza, un motivo de origen divino derivado de la atención a un mendigo de Barcelona y por la que Jesucristo lo recompensó con la aparición de dos doncellas. La primera, le ofreció una corona de rosas, distintivo del gozo y felicidad, y la segunda una corona de espinas, alusiva al sufrimiento, escogiendo la segunda de ellas que se iba a convertir con posterioridad en atributo personal ${ }^{52}$. Debe reseñarse, al respecto, que dicha corona constituye un tipo muy desarrollado en el arte colonial, en virtud del denominado casco de espinas o pileus que se extiende por todo el bloque craneal y partía en su descripción de las propias fuentes evangélicas. Sus atributos habituales se repiten también en esta pintura, desde la custodia referente a la última comunión recibida en su lecho de muerte de la mano del mismo Jesús y a ser el blanco de muchas de sus predicaciones, a la palma martirial jalonada de tres coronas relativas a sus virtudes: castidad, elocuencia y martirio ${ }^{53}$.

52. Louis Réau, Iconografía del arte cristiano. Iconografía de los santos. De la P a la Z. Repertorios(Barcelona: Ediciones del Serbal, 2002), 5: 77-79. 53. Juan Carmona Muela, Iconografía de los santos (Madrid: Istmo, 2003), 390-392. 


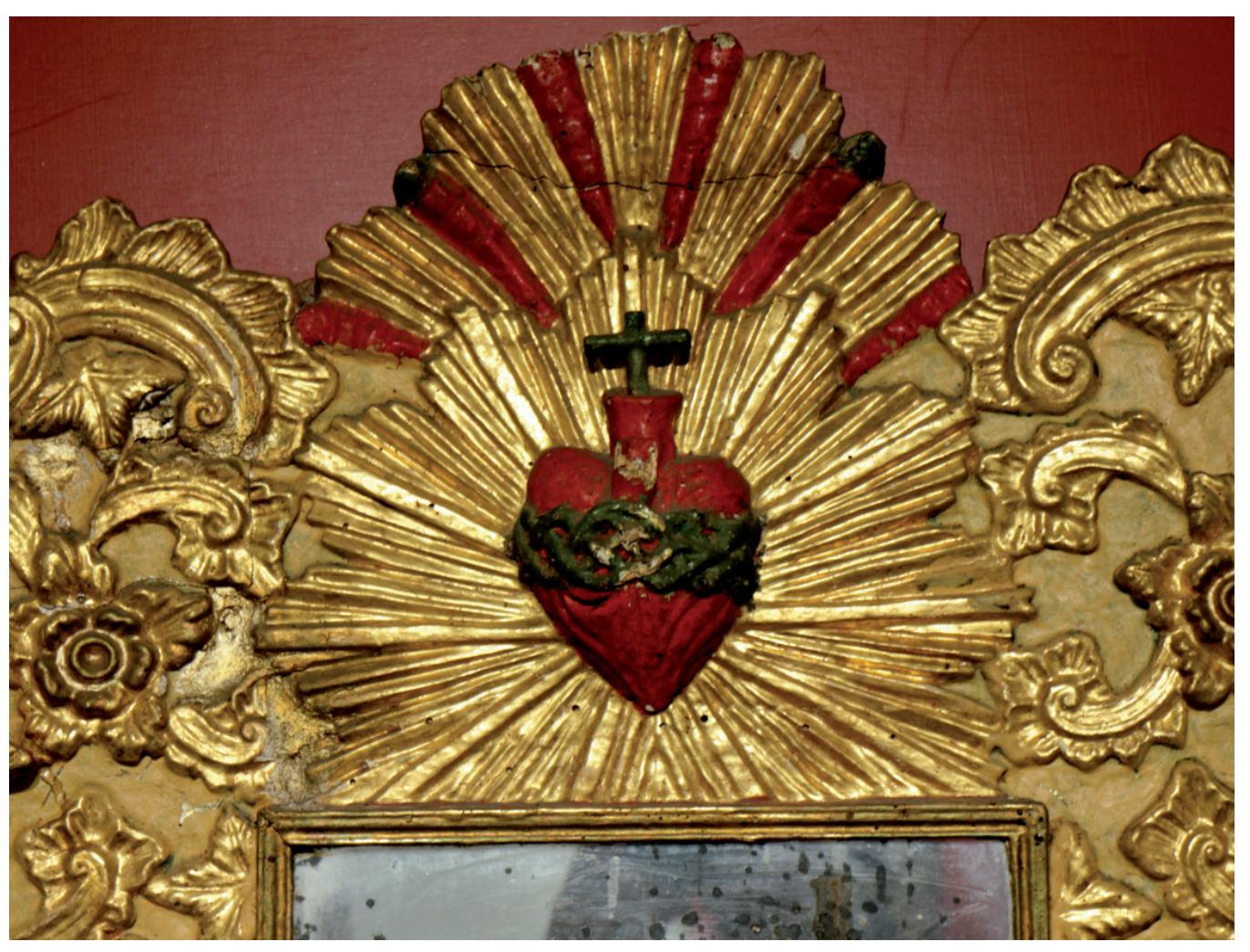

Fig. 10. Pormenor del marco y copete tallado perteneciente al lienzo de la Virgen de la Merced del Museo de Las Conceptas, Cuenca. (Fotografía de los autores).

Por último, no puede dejar de mencionarse el magnífico marco en madera tallada y dorada que orla el lienzo (Fig. 10). Por su estética y minuciosa labor, inserto dentro de la tradición artesanal quiteña y conforme a las corrientes decorativas barroco-rococó al decir de la utilización de rocallas y la incrustación de espejos, estos últimos también asociados simbólicamente a la pureza de María. No obstante, percibimos una flagrante diferencia entre el marco propiamente dicho y el copete que lo remata, por cuanto no existe una continuidad y ajuste a la parte inferior, ni en lo que se refiere al encaje de ambas piezas, ni mucho menos a la concordancia de los elementos ornamentales. De hecho, queda reflejado un cambio de intensidad decorativa entre una y otra, aun cuando comparten algunos de los motivos por su similar cronología. Tampoco coincide demasiado con la temática pictórica de la obra la colocación superior del emblema del corazón doloroso de Jesús, lo que nos lleva a pensar que el referido copete es un añadido que se reaprovechó a partir de los restos de un reducido retablo, hornacina u otro tipo de bien mueble.

\section{Conclusiones}

El análisis de la pintura dedicada a la Virgen de la Merced sita en el Museo de Las Conceptas de Cuenca subraya, una vez más, el destacado papel de las pintoras dentro del panorama artístico colonial de la Edad Moderna. Cierto es que aún queda mucho 
por hacer en este ámbito, pero el denuedo investigador de jóvenes historiadores, y de aquellos/as que ya no lo son tanto aportando un plus en su base experiencial más sólida, están confiriéndole a los estudios de género ya no solo una difusión pública, totalmente necesaria, sino también una visión transversal e interdisciplinar que lo enriquece y permite su observación desde una perspectiva poliédrica. Como casi siempre uno de los principales problemas radica en la ausencia de una amplia documentación, que nos conduzca a profundizar en las autoras y su producción, permitiendo trazar vínculos con las instituciones, mecenas y colegas de profesión, amén de conectar otro tipo de confluencias técnicas, estéticas y/o iconográficas.

Esto es lo que ocurre con el caso de sor María de la Merced, una verdadera desconocida tanto en el ámbito artístico como religioso y de la que solo tenemos, por ahora, la información que ella misma insertó a modo de leyenda en la base de la pintura. Simple reseña histórica o afán de vanagloria, sor María de la Merced legó estos datos reparando en la exposición más o menos pública de la obra, sobre todo si fue ejecutada para formar parte de la clausura. También dentro de estas existían jerarquías entre las componentes de la comunidad, por lo que eran conscientes de la pervivencia de sus hechos, ya fueran espirituales o materiales. Sin embargo, vivir en el microcosmos conventual alejadas del trasiego de la ciudad no les privaba de tener conocimiento de lo que ocurría fuera de los muros del inmueble; es más, participaban a su manera, trascendiendo a esta de los movimientos civiles y populares, de modo que fue frecuente su concurso en el engranaje de las relaciones sociales. Por supuesto, también en el devenir del mundo artístico, desde el mismo momento en que formaban parte de un aprendizaje y de unas tendencias más o menos definidas. Tal vez, la pintura fuera la modalidad más adecuada para una religiosa de clausura por su carácter asequible, material y técnicamente hablando. Pero también una manera perfecta de expresarse desde lo plástico para conectar esos dos mundos, sin dejar nunca de lado la misión religiosa a la que se habían entregado.

\section{Referencias}

\section{Fuentes documentales}

Archivo Histórico Monasterio de Las Conceptas(AHMC). Cuenca. Fondos: Historia del convento. Archivo Nacional de Historia (ANH). Cuenca. Fondos: Historia Cuenca. 


\section{Fuentes bibliográficas}

Aranda Bernal, Ana. "La participación de las mujeres en la promoción artística durante la Edad Moderna." Goya, Revista de Arte, no. 301-302 (2004): 229-240.

Arias Álvarez, José Carlos. Evidente y oculto: viaje por la iconografía del arte colonial ecuatoriano. Guayaquil: Banco Central de Ecuador, 2008.

Báez, Rolando. "Marianismo y mestizaje en la cultura visual chilena. Una aproximación desde la práctica curatorial." En Vírgenes, mártires y santas mujeres, 36-82. Santiago de Chile: Museo La Merced, 2014.

Borchart de Moreno, Christiana Renate. "La imbecilidad y el coraje, la participación femenina en la economía colonial 1780-1830." Revista complutense de historia de América, no. 17 (1991): 167-182.

---. La Audiencia de Quito: aspectos económicos y sociales (siglos XVI-XVIII). Quito: Ediciones del Banco Central y Ediciones Abya-Yala, 1998.

Brunet, José. "La Virgen de la Merced y sus diversos patronazgos en América." Estudios, no. 172-175 (1991): 307-488.

Cano Manrique, Francisco, María Teresa Ruiz Barrera, y Juan Luis Ravé Prieto. La Orden de la Merced en Andalucía (1203-1603-2003). Patrimonio histórico mercedario, en la provincia de Sevilla. Sevilla: Junta de Andalucía, 2003.

Carmona Muela, Juan. Iconografía de los santos. Madrid: Istmo, 2003.

Chacón Zhapán, Juan. Historia del Corregimiento de Cuenca. Cuenca: Banco Central, 1990.

Cordero Íñiguez, Juan. María en las artes cuencanas. Cuenca: Universidad de Cuenca, 2004.

---. Historia de Cuenca y su región. Segunda parte. Vol. 5 de Creación y desenvolvimiento de la gobernación (1777-1809). Cuenca: Universidad-Municipalidad, 2016.

Gallegos de Donoso, Magdalena. Iconografía de la Virgen María en el Arte ecuatoriano. Quito: Museo Banco Central del Ecuador, 1982.

Gisbert, Teresa. El paraíso de los pájaros parlantes: la imagen del otro en la cultura andina. La Paz: Plural editores, 1999.

González Suárez, Federico. Historia General de la República del Ecuador. Vol. 7. Quito: Imprenta del Clero, 1903.

Guede, Lisardo. La Merced (compendio histórico, en 15 lecciones). Málaga: Imprenta J. Ruiz, 1977.

Justo Estebaranz, Ángel. "Advocaciones marianas españolas en el arte de la Real Audiencia de Quito." Atrio. Revista de Historia del Arte, no. 20 (2014): 24-39.

Kennedy Troya, Alexandra. "Mujeres en los claustros: artistas, mecenas y coleccionistas." En Arte de la Real Audiencia de Quito, siglos XVII-XIX. Patronos, comportamientos y comunidades, 22-127. San Sebastián: Nerea, 2002.

Kennedy Troya, Alexandra, y Marcia Sigüenza Crespo. Monasterio de las Conceptas. Catálogo del Archivo Histórico. Cuenca: Fundación Paúl Rivet, 1990.

La Condamine, Charles Maria de. Journal de voyage fait par ordre du Roi, a L'Equateur, servant d'introduction historique a la mesure des trois premiers degrés du méridien. París: Imprimerie Royale, 1751.

López Monsalve, Rodrigo. Cuenca, Patrimonio Cultural de la Humanidad. Cuenca: s. e., 2003.

atrio Revista de Historia del Arte, ำ 26 (2020): 88 - 118

elSSN: 2659-5230. https://doi.org/10.46661/atrio.5096 
Lloret, Gustavo. Museo de Las Conceptas. Un testimonio histórico. Cuenca: Fundación Museo de Las Conceptas, 2009.

Martín Martín, Inmaculada. "Isabel de Santiago: una pintora quiteña del siglo XVII." De Arte. Revista de Historia del Arte, no. 7(2008): 129-152.

Martínez Borrero, Juan. La pintura popular del Carmen. Identidad y cultura en el siglo XVIII. Cuenca: CIDAP, 1983.

Martínez Borrero, Juan, Carmen Ugalde de Valdivieso, y Juan Cordero Íñiguez. De lo divino y lo profano. Arte cuencano de los siglos XVIII y XIX. Cuenca: Ediciones del Banco Central del Ecuador, 1997.

Matovelle, Julio. Historia del culto a Nuestra Señora de las Mercedes en la República del Ecuador. Quito: Tipografía Salesiana, 1910.

Montes Sánchez, Macarena. "La participación de la mujer en el patrimonio artístico de Cuenca a fines de la Colonia." Boletín de la Academia Nacional de Historia, XCl, no. 188 (2013): 47-86.

Morales Muñiz, María Dolores-Carmen. "El simbolismo medieval en la cultura medieval." Espacio, Tiempo y Forma, serie III, no. 9 (1996): 229-255.

Moreno de Dávila, Eulalia. La colección pictórica del Museo de las Conceptas de Cuenca. Cuenca: Universidad del Azuay, 2005.

Navarro, José Gabriel. La escultura en el Ecuador durante los siglos XVI, XVII y XVIII. Quito: Ed. Fundación José Gabriel Navarro y TRAMA, 2006.

Ortiz Crespo, Antonio. Ciudad de Quito. Guía de arquitectura. Vol. 2. Quito: Municipio de Quito; Sevilla: Embajada de España, 2004.

Paniagua Pérez, Jesús. "Las pinturas murales del convento de la Concepción de Cuenca (Ecuador)." Cuadernos de Arte Colonial, no. 7 (1991): 109-127.

---. "Iconografía mercedaria en la colección Crespi de Cuenca (Ecuador)." Estudios, no. 192 (1996): 35-55.

Paniagua Pérez, Jesús, y Deborah L. Truhan. Oficios y actividad paragremial en la Real Audiencia de Quito (1557-1730). El corregimiento de Cuenca. León: Universidad, 2003.

Réau, Louis. Iconografía del arte cristiano. Iconografía de los santos. De la P a la Z. Repertorios. Vol. 5. Barcelona: Ediciones del Serbal, 2002.

"Reglas de las religiosas de la Pura y Limpia Concepción." Revista del Archivo Nacional de Historia, sección Azuay, no. 7 (1987): 146-249.

Rodríguez Docampo, Diego. "Descripción y relación del Estado eclesiástico del Obispado de San Francisco de Quito, que se ha hecho por mandado del Rey Nuestro Señor en virtud de su Real Cédula dirigida al IIImo. Sr. D. Agustín de Ugarte Saravia, Obispo de Quito, del Consejo de S. M. Por cuya orden la hizo Diego Rodríguez Docampo Clérigo, Presbítero Secretario del Venerable Deán y Cabildo de aquella Catedral. Año de 1650." En Relaciones geográficas de Indias, 207-322. Madrid: Ed. Atlas, 1965.

Ruiz Barrera, María Teresa. "Notas iconográficas sobre la Virgen de la Merced. Sus artes plásticas en Andalucía occidental." En Regina mater. Estudios históricos, artísticos y antropológicos de advocaciones marianas, 569-588. Córdoba: Litopress, 2016.

Sanfuentes Echeverría, Olaya. "Las frutas en la pintura colonial de Chile: más que decoración, simbolismo." Ensayos. Historia y teoría del arte, no. 24 (2013): 84-100. 
Stratton-Pruitt, Suzanne L., ed. El arte de la pintura en Quito. Philadelphia: Saint Joseph's University Press, 2012.

Truhan, Deborah L. y Luz María Guapizaca Vargas. Libro de Cabildos de la ciudad de Cuenca, 15971603. Cuenca: Casa de la Cultura Ecuatoriana Benjamín Carrión y Alcaldía de Cuenca, 2010.

Vargas, José María. El arte ecuatoriano. Puebla: Editorial J. M. Cajica, 1959.

---. El arte religioso en Cuenca. Quito: Editorial Santo Domingo, 1967.

---. Patrimonio artístico ecuatoriano. Quito: Trama Ediciones, 2005.

Viforcos Marinas, María Isabel. "El beaterio quiteño de Nuestra Señora de La Merced y sus fallidos intentos de transformación del convento (1730-1758)." En I Congreso Internacional del monacato femenino en España, Portugal y América: 1492-1992, 357-366. León: Universidad de León, 1993.

---."Luces y sombras de la vida monástica femenina: las concepcionistas de Cuenca(Ecuador)en el siglo XVIII." Revista Estudios Humanísticos: geografía, historia, arte, no. 17 (1995): 311-328.

Zuriaga Senent, Vicent. La imagen devocional en la Orden de Nuestra Señora de la Merced. Tradición, formación, continuidad y variantes. Valencia: Servicio de Publicaciones, 2005. 